Published in final edited form as:

J Am Chem Soc. 2015 December 23; 137(50): 15742-15752. doi:10.1021/jacs.5b07910.

\title{
Mimicking Ribosomal Unfolding of RNA Pseudoknot in a Protein Channel
}

\author{
Xinyue Zhang ${ }^{\dagger}$, Xiaojun Xu‡, Zhiyu Yang ${ }^{\S}$, Andrew J. Burcke ${ }^{\dagger}$, Kent S. Gates $^{\S}$, Shi-Jie \\ Chen ${ }^{*}, \neq$, and Li-Qun Gu ${ }^{*}, \dagger$ \\ tDepartment of Bioengineering and Dalton Cardiovascular Research Center, University of \\ Missouri, Columbia, Missouri 65211, United States \\ ‡Department of Physics, Department of Biochemistry, and Informatics Institute, University of \\ Missouri, Columbia, Missouri 65211, United States \\ $\S$ Department of Chemistry and Department of Biochemistry, University of Missouri, Columbia, \\ Missouri 65211, United States
}

\begin{abstract}
Pseudoknots are a fundamental RNA tertiary structure with important roles in regulation of mRNA translation. Molecular force spectroscopic approaches such as optical tweezers can track the pseudoknot's unfolding intermediate states by pulling the RNA chain from both ends, but the kinetic unfolding pathway induced by this method may be different from that in vivo, which occurs during translation and proceeds from the $5^{\prime}$ to $3^{\prime}$ end. Here we developed a ribosomemimicking, nanopore pulling assay for dissecting the vectorial unfolding mechanism of pseudoknots. The pseudoknot unfolding pathway in the nanopore, either from the $5^{\prime}$ to $3^{\prime}$ end or in the reverse direction, can be controlled by a DNA leader that is attached to the pseudoknot at the $5^{\prime}$ or $3^{\prime}$ ends. The different nanopore conductance between DNA and RNA translocation serves as a marker for the position and structure of the unfolding RNA in the pore. With this design, we provided evidence that the pseudoknot unfolding is a two-step, multistate, metal ion-regulated process depending on the pulling direction. Most notably, unfolding in both directions is ratelimited by the unzipping of the first helix domain (first step), which is Helix-1 in the $5^{\prime} \rightarrow 3^{\prime}$ direction and Helix-2 in the $3^{\prime} \rightarrow 5^{\prime}$ direction, suggesting that the initial unfolding step in either pulling direction needs to overcome an energy barrier contributed by the noncanonical triplex base-pairs and coaxial stacking interactions for the tertiary structure stabilization. These findings provide new insights into RNA vectorial unfolding mechanisms, which play an important role in biological functions including frameshifting.
\end{abstract}

\section{Graphical abstract}

\footnotetext{
*Corresponding Authors; Email: gul@missouri.edu, ; Email: chenshi@missouri.edu ASSOCIATED CONTENT

Supporting Information

The Supporting Information is available free of charge on the ACS Publications website at DOI: 10.1021/jacs.5b07910. More typical events for 5'-PK and $3^{\prime}$-PK and their blocking level, single strand DNA and RNA blocking levels, event duration's voltage dependence, typical events for $2 \mathrm{H}, 5^{\prime}$-PK and $3^{\prime}$-PK events and duration in near physiological condition, various blocking events in additional to pseudoknot blocking events and their percentage, energy parameters used for the KMC simulations. (PDF) The authors declare no competing financial interest.
} 

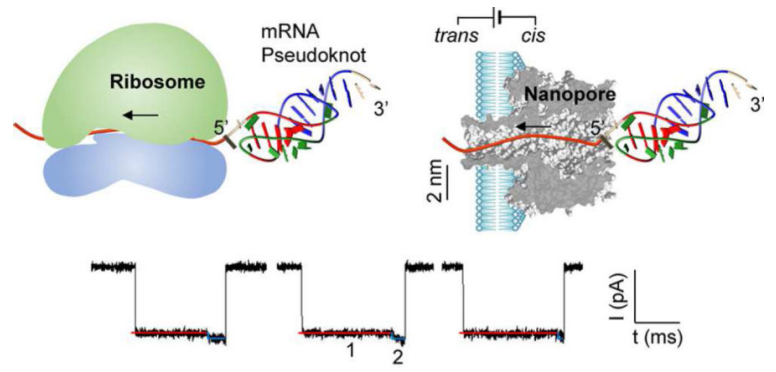

1: $1^{\text {st }}$ helix unzipping and non-canonical interaction breaking

2: $2^{\text {nd }}$ helix stem unzipping

\section{INTRODUCTION}

Gene expression can be regulated through folding and unfolding mRNA tertiary structures. ${ }^{1-6}$ Pseudoknots are a fundamental structure found in almost all classes of RNAs $^{7-15}$ such as human telomerase RNA, ${ }^{6}$ self-splicing introns of ribozymes ${ }^{16,17}$ and many noncoding RNAs. ${ }^{18,19}$ The typical H-type pseudoknot is formed by base-pairing between the loop of a hairpin and a complementary fragment outside the stem in the RNA chain. Such a structure, containing multiple stemloops, can be stabilized through noncanonical triplex base pairs and coaxial stacking interactions. ${ }^{6,20-22}$ Remarkably, in the frameshifting mechanism for translational control of viral protein synthesis (e.g., HIV, SARS and HCV), ${ }^{7,9,11,14}$ the ribosome needs to disrupt a downstream pseudoknot in a retroviral RNA to continue the translation with a shifted open reading frame (ORF). This RNA unfolding-regulated mechanism enables expression of different proteins from the same viral RNA genome for virus replication and proliferation. Pseudoknots are also the basic structures of riboswitches (e.g., PreQ-I), a class of regulatory fragments in mRNAs that can change conformation upon binding a small metabolic molecule for protein expression modulation (for a review see ref 23 and references therein). Therefore, understanding the mechanism by which pseudoknots unfold enable the development of new antiviral drugs, which reduce or eliminate virus production ${ }^{24-26}$ by modulating the stability of RNA structures. ${ }^{27-31}$

Many studies using thermodynamic analysis ${ }^{6,12,32-34}$ and computer simulations ${ }^{20-22,35-37}$ have produced a large amount of information linking the kinetics and thermodynamics of pseudoknots to their functional properties. ${ }^{38,39}$ Recently, the molecular force spectroscopes, e.g., optical tweezers and AFM, have been successfully applied to the study of pseudoknot unfolding kinetics. ${ }^{40-45}$ By pulling the pseudoknot from both ends, this approach can identify the intermediate states along the folding pathway. ${ }^{46-48}$ However, current methods also have limitations. Heating or pulling from both ends of molecules may disrupt a RNA structure starting from the most unstable regions, and the relative stabilities of different regions determine their unfolding order. ${ }^{21,49}$ This unfolding pathway could differ from that in vivo, in which the pseudoknot in mRNA undergoes a vectorial unfolding process, ${ }^{50}$ i.e., directional unfolding along the RNA backbone caused by the ribosome in the $5^{\prime} \rightarrow 3^{\prime}$ direction. 
In this report, we investigated a ribosome-mimicking, protein nanopore-based pulling assay for dissecting pseudoknot's vectorial unfolding mechanism (Figure 1). In cells, the ribosome forms a channel to embrace mRNA for translation from $5^{\prime}$ to $3^{\prime}$ end (Figure 1a). Similarly, the a-hemolysin protein pore is $1.4 \mathrm{~nm}$ wide in the constrictive region ${ }^{51}$ (Figure $1 \mathrm{~b}$ ). Such a pore size only allows translocation of single-stranded nucleic acids, ${ }^{52}$ but folded nucleic acids must unfold to pass through the pore. ${ }^{53-55}$ In the past two decades, the nanopore translocation of various DNAs and RNAs, ${ }^{52,56-60}$ including long RNAs (under denaturing conditions) ${ }^{61}$ and tRNAs, ${ }^{62}$ have been extensively studied, driven by the goal of the next generation sequencing. ${ }^{63,64}$ Furthermore, the nanopore has been developed as a force spectroscopy for exploring protein-nucleic acid interactions, ${ }^{65}$ unfolding of proteins ${ }^{66,67}$ and unzipping of nucleic acid structures such as hairpins, ${ }^{68,69}$ G-quadruplex, ${ }^{53-55,70}$ and microRNAs. ${ }^{71,72}$ Parallel to these efforts, the methodology of nanopore force spectroscopy (voltage-ramp) has been established for nucleic acids kinetic analysis. ${ }^{41,73-75}$ These prior studies provide a solid basis for elucidating nanopore unfolding of RNA tertiary structures. Recently, the braked translocation of tRNAs in the nanopore has been reported ${ }^{62}$ for the purpose of detecting tRNA population, but the RNA unfolding mechanisms have not been elucidated.

In the current study, the RNA pseudoknot was forced to unfold either from the $5^{\prime}$ to $3^{\prime}$ end (the same as ribosome-induced unfolding) or in the reverse direction, controlled by a DA leader covalently attached to the $5^{\prime}$ or $3^{\prime}$ end of pseudoknot. Because of the different nanopore conductance for DNA and RNA translocation, we were able to monitor the position of unfolded RNA in the pore, therefore determining the pseudoknot's stability, tracking its stepwise unfolding and translocation, and identifying intermediate states along the unfolding pathway (Figure 1c). Importantly, the different unfolding kinetics observed between two pulling directions allows us to identify noncanonical interactions involved in pseudoknot's stability.

Our target is the gene 32 mRNA pseudoknot of bacteriophage $\mathrm{T} 2^{76}$ (Figure 1d). This short RNA contains all the structural elements and interactions needed for pseudoknot assembly, therefore providing a good model for studying the RNA unfolding. T2 pseudoknot's structure is highly similar to other pseudoknots, including those involved in viral frameshifting (e.g., HIV), ${ }^{39}$ making it possible to study nanopore-based unfolding of these critical RNA structures and their mechanisms for controlling gene regulation.

\section{RESULTS AND DISCUSSION}

\section{Construction of DNA-Tagged Pseudoknots and Nanopore Signatures}

The 36-nt T2 pseudoknot (Figure 1d) comprises two short helical stems, H1 at the $5^{\prime}$ end (5bp) and $\mathrm{H} 2$ at the $3^{\prime}$ end (7-bp). ${ }^{76}$ The inner end of $\mathrm{H} 1$ and the outer ( $3^{\prime}$-terminal) end of $\mathrm{H} 2$ are connected via a single-nucleotide loop L1 (A8), which makes a sharp turn associated with a strong structural tension. The outer (5'-terminal) end of $\mathrm{H} 1$ and the inner end of $\mathrm{H} 2$ are linked via another loop L2 (7 nts). L2 spans across the shallow groove of H1 to form tertiary interactions with $\mathrm{H} 1$ through noncanonical base pairing, making $\mathrm{H} 1$ virtually a stable triplex. Such a structure allows coaxial stacking of $\mathrm{H} 1$ and $\mathrm{H} 2$ on each other, forming a long quasi-continuous helix with surprisingly high stability. ${ }^{76}$ 
We attached a Poly(CAT $)_{10}$ leader to the $5^{\prime}$ end or $3^{\prime}$ end of the pseudoknot RNA to form DNA-RNA chimeras 5'-PK and 3'-PK (Table 1, Figure 2a). Under a transmembrane voltage, the DNA leader is captured in the nanopore and drives the unfolding of the downstream pseudoknot from the $5^{\prime}$ to $3^{\prime}$ end for $5^{\prime}$-PK, which mimics the ribosomal unfolding direction, and from the $3^{\prime}$ to $5^{\prime}$ end for $3^{\prime}-\mathrm{PK}$. The pulling force on DNA/RNA in the pore is $\sim 10 \mathrm{pN}$ at $120 \mathrm{mV}$ (Figure S1 for force evaluation), which is consistent with the force in prior nanopore pulling experiment, ${ }^{77}$ and similar to the force for pseudoknot unfolding in the force spectroscopy experiment. 46

Monitored at $+120 \mathrm{mV}$ in $1 \mathrm{M} \mathrm{NaCl}$ and $10 \mathrm{mM} \mathrm{MgCl}_{2}$, both 5'-PK and $3^{\prime}$-PK presented on cis side of the nanopore generated a two-level blocking event (Figure $2 \mathrm{~b}$ and c). Its conductance always started at Level-1, and terminated at Level-2, which was slightly lower than Level-1. The Level-1 stage dominated the entire block duration. The relative conductance $\left(I / I_{0}\right)$ of Level-1 and Level-2 was $15 \pm 1 \%$ and $9.7 \pm 0.9 \%$ for $5^{\prime}-\mathrm{PK}$, and 13 $\pm 1 \%$ and $9.2 \pm 1.5 \%$ for $3^{\prime}$-PK (Figure $3 \mathrm{a}$ and Figure S2). This block pattern was not observed for either the DNA leader alone or a short linear form RNA without a tertiary structure (Figure S3), and was distinct from the signal for nanopore unzipping of a hairpin ${ }^{68}$ or a double-stranded oligonucleotide. ${ }^{72,77,78}$ We hypothesize that this unique current pattern is the signature of the chimeras that form a pseudoknot, and reveals the trapping, unfolding and translocation of the pseudoknot in the nanopore.

First, the Level-1 conductance for $5^{\prime}-\mathrm{PK}\left(I / I_{0}=15 \pm 1 \%\right)$ and $3^{\prime}-\mathrm{PK}(13 \pm 1 \%)$ was similar to the blocking level of DNA translocation $\left(I / I_{0}=17 \pm 1 \%\right)$ (Figure 3a), suggesting that Level-1 originates from the entrapment of the DNA leader in the constrictive $\beta$-barrel ${ }^{51}$ (Figure S1). Notably, $3^{\prime}$-PK had a slightly lower Level-1 conductance compared to 5'-PK. This is consistent with a previous observation that the $3^{\prime} \rightarrow 5^{\prime}$ DNA translocation reduced more conductance than the $5^{\prime} \rightarrow 3^{\prime}$ translocation. ${ }^{79}$ Furthermore, as the voltage increased from $+120 \mathrm{mV}$ to $+180 \mathrm{mV}$, the signature duration ( $\tau$ ) was consistently shortened by 10 -fold from $98 \pm 9 \mathrm{~ms}$ to $8.3 \pm 2.1 \mathrm{~ms}$ for $5^{\prime}-\mathrm{PK}$, and 30 -fold from $350 \pm 50 \mathrm{~ms}$ to $12 \pm 2 \mathrm{~ms}$ for $3^{\prime}$ PK (Figure S4), indicating that the folded chimera is destabilized by the voltage applied and unfolds under the pulling. As the unfolded RNA enters the $\beta$-barrel in place of DNA, the nanopore current is transitioned to Level-2 with lower conductance, because RNA translocation produced deeper blocking level than DNA ${ }^{72}$ (Figure 3a and Figure S3). Overall, Level-1 and Level-2 in the current pattern are signals for sequential translocation of the DNA leader and unfolded RNA in the nanopore stem.

In addition to pseudoknot signatures, the chimeras also produced different nonpseudoknot block patterns (Figure S6). We found that $56 \%$ of the $5^{\prime}$-PK signals were pseudoknot signatures, and $11 \%$ were a type of short blocks ( $18 \pm 3 \mathrm{~ms})$ similar to the Level-2 current in the pseudoknot signature, supporting that these blocks are generated by partially folded hairpins that unzip in the nanopore. The remaining $27 \%$ spikes $(0.3 \pm 0.2 \mathrm{~ms})$ and $6 \%$ spikes with a shoulder $(1.7 \pm 0.2 \mathrm{~ms})$ should correspond to 1- and 2-step translocation of nucleic acids in extended conformations. ${ }^{80}$ Similar structural and block pattern diversity was also identified for 3'-PK (Figure S6). 
To better understand the chimera configurations in the nanopore, we investigated the T2 pseudoknot without tags (T2-PK, Table 1). Unlike tagged pseudoknot, T2-PK only generated nonpseudoknot short blocks $\left(I / I_{0}=10 \pm 2 \%, \sim 0.1-10 \mathrm{~ms}\right.$, Figure $\mathrm{S} 5$ and Figure S6), suggesting that the pseudoknot structure itself cannot be trapped into the cis vestibule. This is in contrast to the DNA G-quadruplex, which can be trapped in the nanocavity and partially reduce the pore current $\left(I / I_{0} \sim 50 \%\right) .{ }^{54}$ Therefore, it was expected that when $5^{\prime}$ - or $3^{\prime}$-PK is captured by the nanopore, its pseudoknot domain should be anchored at the cis entrance; and the chimera cannot be trapped in the opposite orientation with pseudoknot heading into the pore. By analyzing the block frequency, we estimated that $40 \%$ of T2-PK molecules fold into pseudoknot (Figure S6). This population is similar to the $5^{\prime}$ - and 3'-PK pseudoknots, suggesting that the tag in chimeras does not significantly affect pseudoknot formation.

\section{Vectorial Unfolding Pathways of T2 Pseudoknot}

Pulled by the DNA leader, $5^{\prime}$-PK is expected to unfold in the $5^{\prime} \rightarrow 3^{\prime}$ direction, with H1, which is directly connected to the DNA leader, unfolds first during the Level-1 stage (94 \pm 6 $\mathrm{ms}$, Figure $2 \mathrm{~b}$ ). The unzipping of $\mathrm{H} 1$ releases a hairpin that consists of the $\mathrm{H} 2$ stem and an enlarged loop comprising L2 and the G16-A20 domain dissociated from H1. The unzipping of $\mathrm{H} 1$ also releases the $5^{\prime}$ end G1-A8 domain, which acts as an overhang of $\mathrm{H} 2$ to enter the $\beta$-barrel, generating the Level-2 conductance. Pulled by the overhang, the stem of such a "fishhook" hairpin would be trapped into the cis vestibule, according to the literature. ${ }^{81}$ Therefore, the Level-1/Level-2 transition marks the occurrence of pseudoknot unfolding to a partially folded hairpin structure. The Level- 2 stage $(4.1 \pm 0.3 \mathrm{~ms})$ terminates upon unzipping of the $\mathrm{H} 2$ hairpin. The time scale for unzipping this 7-bp RNA hairpin is consistent with unzipping a 7-10-bp hairpin in previous report ( 10 ms). ${ }^{68}$ In contrast to $5^{\prime}$ $\mathrm{PK}, 3^{\prime}$-PK is expected to unfold in the $3^{\prime} \rightarrow 5^{\prime}$ direction. The $3^{\prime}$ end $\mathrm{H} 2$ that connects to the DNA leader unfolds first during the Level-1 stage $(330 \pm 40 \mathrm{~ms})$, resulting in a hairpin with $\mathrm{H} 1$. As the unfolded RNA domain is pulled into the $\beta$-barrel, the conductance is transitioned to Level-2 for unzipping $\mathrm{H} 1$ of the hairpin $(21 \pm 3 \mathrm{~ms})$. In summary, $5^{\prime}-\mathrm{PK}$ and $3^{\prime}-\mathrm{PK}$ are unfolded along different pathways. For the unfolding in the $5^{\prime} \rightarrow 3^{\prime}$ direction $\left(5^{\prime}-\mathrm{PK}\right)$, Level-1 is for unzipping $\mathrm{H} 1$ and Level-2 for H2; for the opposite $3^{\prime} \rightarrow 5^{\prime}$ direction ( $3^{\prime}$-PK), Level-1 is for unzipping $\mathrm{H} 2$ and Level-2 for $\mathrm{H} 1$.

The duration of each blocking level further reveals intermediate unfolding states. For both 5'-PK and 3'-PK, the durations of Level-1 and Level-2 stages can be better fitted with a two components (Figure $3 \mathrm{c}$ and d), rather than single component exponential distribution. Such a duration distribution suggests that there exists at least one intermediate state in both Level-1 and Level-2 stages. The intermediate state in the Level-1 stage probably corresponds to a partially unzipped state of $\mathrm{H} 1$ for $5^{\prime}-\mathrm{PK}$ or $\mathrm{H} 2$ for $3^{\prime}-\mathrm{PK}$. The partially unfolded state of $\mathrm{H} 1$ has been identified using molecular dynamic simulation. ${ }^{37}$ At a temperature of $350 \mathrm{~K}, \mathrm{H} 1$ first unfolded in the outer region (U3-A20 pair), and underwent a reversible disruptionreformation process. The final unfolding of $\mathrm{H} 1$ started from its inner region close to the loop and proceeded from the inner region outward. The intermediate state identified in Level-2 stage occurs during the unzipping of the remaining (second) stem, $\mathrm{H} 2$ in $5^{\prime}-\mathrm{PK}$ and $\mathrm{H} 1$ in $3^{\prime}$ PK. The intermediate state during hairpin unzipping in the nanopore has not been reported 
previously. We interpret that when the hairpin is squeezed into the pore, the large loop may adjust its configuration. This process may involve new base-pair formation within the loop to facilitate the unzipping of the hairpin (Simulation result below).

\section{Tertiary Interactions for Pseudoknot Stabilization}

The block patterns reveal that, in both unfolding directions, the Level-1 stage is much longer than the Level-2 stage (Figure 2 and 3). For 5'-PK, Level-1 was 24-fold longer than Level-2, and for 3 '-PK, Level-1 was 16-fold longer than Level-2, indicating that the unfolding in both directions is rate-limited by the first step. The disruption of the first helix determines the barrier of the overall unfolding process. As shown in Figure 1d, both helices involve rich tertiary interactions, such as the loop-helix base triples and helix-helix coaxial stacking interactions. Besides the stability of the helix alone, the disruption of a helix also involves breaking tertiary interactions. This finding suggests that there are more factors that could influence the unfolding time than the helix stability alone. ${ }^{21}$ One potential factor could be the asymmetry of tertiary interactions, including loop-helix base triples and coaxial stacking between the two helices. Here we utilized three mutant RNAs to demonstrate this effect.

Mutations that disrupt loop-stem tertiary contacts have been found to dramatically reduce biological activity, often due to the decreasing thermodynamic stability of the native pseudoknot. ${ }^{13,33,82-88}$ To investigate the effect of the loop-stem tertiary contacts on the unfolding kinetics of the T2 pseudoknot, we substituted L2 with a poly(U) loop. Elastic property studies have shown that a single-stranded RNA poly(U) chain tends to be more disordered with weaker loopstem tertiary interactions. ${ }^{89,90}$ Similar to $5^{\prime}$ - and $3^{\prime}$-PK, we attached a DNA leader to either end of the mutant pseudoknot to form the chimeras $5^{\prime}$-PKmut and 3'-PK-mut (Figure 4a and d). Both mutant chimeras generated the two-level unfolding signatures (Figure $4 \mathrm{~b}$ and e). However, the substitution of $\mathrm{L} 2$ with the poly(U) loop weakens loop-stem tertiary interactions, causing reduction in the dominating Level-1 duration (prior to the $\mathrm{PK} \rightarrow \mathrm{HP}$ transition) compared to their wild-type (WT) counterparts, with reduction ratios of $4.3(94 \pm 6 \mathrm{~ms} / 22 \pm 4 \mathrm{~ms})$ and $4.5(330 \pm 40 \mathrm{~ms} / 73 \pm 10 \mathrm{~ms})$ for the $5^{\prime}$ - and $3^{\prime}$-unfolding, respectively (Figure $4 \mathrm{c}$ and $\mathrm{f}$ ), This result supports the possible correlation between the loop-helix tertiary interaction and the unfolding kinetic barrier. The barrier difference with respect to the corresponding WT chimeras was $0.84 \mathrm{kcal} \cdot \mathrm{mol}^{-1}$ for unfolding in the $5^{\prime} \rightarrow 3^{\prime}$ direction (5'-PK vs $5^{\prime}$-PK-mut), and $0.86 \mathrm{kcal} \cdot \mathrm{mol}^{-1}$ in the $3^{\prime} \rightarrow 5^{\prime}$ direction ( $3^{\prime}$-PK vs $3^{\prime}$-PK-mut) (Table 2), suggesting that the unfolding of T2 pseudoknot from either direction needs to overcome a similar initial barrier to break the loop-stem tertiary interaction.

The poly $(\mathrm{U})$ loop substitution also influences the Level-2 duration (prior to the $\mathrm{HP} \rightarrow$ coil transition). For the $5^{\prime}$ pulling, poly(U) is located within the 12-nt hairpin loop, which prevents the proper base pairing and the formation of the intermediate structure. This large loop may prolong the Level-2 duration $\left(6.5 \pm 1.2 \mathrm{~ms}\right.$ for $5^{\prime}$-PK-mut compared with $4.1 \pm 0.3$ $\mathrm{ms}$ for $5^{\prime}-\mathrm{PK}$ ) due to the larger entropic barrier for loop compaction. For the $3^{\prime}$ pulling, even though the substitution of the L2 loop with poly(U) does not change the pathway of the HP $\rightarrow$ coil transition, the Level-2 duration decreased (7.8 $\pm 1.1 \mathrm{~ms}$ for $3^{\prime}$-PK-mut compared with $21 \pm 3 \mathrm{~ms}$ for $\left.3^{\prime}-\mathrm{PK}\right)$, probably because the $3^{\prime}$-poly(U) tail of the helix is highly 
flexible, causing an adjustable stretching of the chain and hence an efficient pulling. In another explanation, after the initial H2 unzipping (Level-1), the H1-L2 tertiary interactions may not be fully broken while the unfolded RNA domain has already entered the $\beta$-barrel (Level-2). Therefore, the Level-2 stage may involve the breaking of H1-L2 interactions in addition to $\mathrm{H} 1$ unzipping.

To eliminate the loop-helix tertiary interactions, we constructed a truncated RNA duplex $2 \mathrm{H}$ without loops (Table 1 and Figure 5a). 2H contains all 5 bps from $\mathrm{H} 1$ and 7 bps from $\mathrm{H} 2$. Since the two stems in the pseudoknot are coaxially stacked on each other to form a long (12 bps) quasi-continuous helical 3D structure, $2 \mathrm{H}$ should keep the stability of the (coaxially stacked) helical part but lack loop-helix tertiary interactions. This RNA duplex can be unzipped upon pulling by the attached DNA leader. The resulting signature reveals a multistep unzipping and translocation process (Figure 5b and Figure S7), which has been dissected in our previous studies. ${ }^{72}$ The $2 \mathrm{H}$ signature $(11 \pm 2 \mathrm{~ms}$, Figure $5 \mathrm{c})$ was 8.9 - and 31-fold shorter than $5^{\prime}$ - and $3^{\prime}$-PK signatures, and 2.6- and 8-fold shorter than $5^{\prime}$ - and $3^{\prime}$-PKmut signatures. Therefore, the unfolding of $5^{\prime}-\mathrm{PK}$ and $3^{\prime}-\mathrm{PK}$, which contains coaxially stacking and strong loop-helix interactions, is harder than the unfolding of the $5^{\prime}$-PK-mut and 3'-PK-mut, which may involve weak loop-helix interactions, and much harder than unfolding of $2 \mathrm{H}$, which has no loop-involved tertiary interactions. With respect to $2 \mathrm{H}$, an additional energy barrier of 1.3 and $2.0 \mathrm{kcal} \cdot \mathrm{mol}^{-1}$ are needed for $5^{\prime}$ - and $3^{\prime}$-PK (Table 2). This additional energy cost may correspond to the disruption of loop-stem tertiary interactions, as suggested by previous simulation results. ${ }^{20}$ Notably, $3^{\prime}$-PK requires a longer time $(330 \mathrm{~ms})$ than $5^{\prime}$-PK $(94 \mathrm{~ms})$ to unfold in the rate-limiting Level-1 stage. This difference may be primarily caused by the different stabilities of the two helices. Breaking the 7-bp H2 (as the first step for unfolding $3^{\prime}$-PK) is slower than breaking the less stable 5bp H1 (as the first step for unfolding $5^{\prime}$-PK).

\section{Kinetics Simulation}

To better understand the mechanism of RNA pseudoknot unfolding through a nanopore, we used kinetic Monte Carlo (KMC) method (ref 91 and therein for algorithm) to simulate the unfolding process. The KMC method is powerful to provide detailed transition pathways and the distribution of unfolding time. ${ }^{91}$ We used the first passage time (FPT), i.e., the time for the first formation of a conformation from the initial conformations to characterize the unfolding time. For a specific target conformation, FPT is a random variable, but the mean FPT can be directly compared with the mean dwell time obtained by experiments. In the pseudoknot unfolding process, electric force on the DNA leader $\left(\operatorname{Poly}(\mathrm{CAT})_{10}\right)$ in the nanopore exerts a pulling force on the RNA pseudoknot. To simulate the effect of the electric pulling force on the kinetic rates, we introduced a voltage $V$-dependent free energy change $g(V)$ generated by the pulling force. The rate constant for the opening and closing of a base stack ${ }^{91,92}$ was calculated based on the Metropolis rule: ${ }^{93} k=\min \left(k_{0}, k_{0} e^{-\Delta G(V) / k_{\mathrm{B}} T}\right)$, where $\Delta G(V)=\Delta G(0)+g(V)$ and $\Delta G(0)$ is the force-free free energy difference between the closed and open states of a base stack. The kinetic barrier was modified by the additional change $g(V)$ due to the external electric field $V$. The prefactor $k_{0}$ is the attempt frequency, $k_{\mathrm{B}}$ is the Boltzmann constant, and $T$ is the temperature. To model the helix zipping, we followed Cocco et al. ${ }^{94}$ and restricted the initialization of the unzipping at the helix end 
where the force is applied. Therefore, a typical conformation in the unfolding process of an $N$-bp pseudoknot has the first $n$ base pairs opened along the pulling direction and the rest $N$ $n$ base pairs closed. After the disruption of the first helix, the hairpin loop of the remaining helix is enlarged. Depending on the sequence, the enlarged hairpin loop may allow new base pairs and mismatches to be formed within the loop, resulting in a stable stem-loop structure with smaller loop size. The enthalpies and entropies for such conformations were predicted using the V-fold model ${ }^{95}$ (Table S1).

As shown in Figure 6, the pseudoknot unfolded through different pathways for different pulling directions. For the pulling from the $5^{\prime}$ end, the $5^{\prime} \mathrm{H} 1$ (shown in red) was first disrupted, causing the conformational transition from the pseudoknot to a 12-nt hairpin $\mathrm{HP}_{1}{ }^{\left(5^{\prime}\right)}$. Because of the formation of the base pairs within its loop, $\mathrm{HP}_{1}{ }^{\left(5^{\prime}\right)}$ quickly folded into a compact stem-loop structure $\mathrm{HP}_{2}{ }^{\left(5^{\prime}\right)}$, which contains a 1-nt bulge loop and a 5-nt hairpin loop. Finally further pulling from the $5^{\prime}$ side caused the disruption of the base pairs in $\mathrm{HP}_{2}{ }^{\left(5^{\prime}\right)}$. Pulling from the $3^{\prime}$ end led to a different intermediate hairpin $\mathrm{HP}^{\left(3^{\prime}\right)}$. In contrast to $\mathrm{HP}_{1}{ }^{\left(5^{\prime}\right)}$, the sequence of the 8-nt large loop in $\mathrm{HP}^{\left(3^{\prime}\right)}$ does not allow the formation of stable intraloop base pairs.

Furthermore, the predicted unfolding times from our KMC simulations were consistent with the experimental data, except for the time for the unfolding of $\mathrm{HP}^{\left(3^{\prime}\right)}\left(\tau_{2}{ }^{\left(3^{\prime}\right)}\right)$ due to the reason explained in the following. The large size of the 8-nt loop in $\mathrm{HP}^{\left(3^{\prime}\right)}$ may cause the structure to pause at the cis opening of the nanopore. Translocation would occur only after the loop forms a more compact conformation (Figure 6). The time duration required for loop-compaction is more pronounced for $\mathrm{HP}^{\left(3^{\prime}\right)}$ than for $\mathrm{HP}_{2}{ }^{\left(5^{\prime}\right)}$ due to the larger loop size (8 nts) and hence a larger entropic barrier. Without considering the $\mathrm{HP}^{\left(3^{\prime}\right)}$ pause, the KMC simulation predicted a dwell time of $0.8 \mathrm{~ms}$. The pause of $\mathrm{HP}^{\left(3^{\prime}\right)}$ due to the large loop size may account for the difference between the experimental $\tau_{2}{ }^{\left(3^{\prime}\right)}$ result $(21 \mathrm{~ms})$ and the KMC result (0.8 ms).

\section{Regulation of Pseudoknot Stability by Magnesium lons and in Near-Physiology lonic Condition}

$\mathrm{Mg}^{2+}$ ions are critical for stabilizing tertiary structures and regulating biological functions of RNA structures such as pseudoknots ${ }^{34}$ and riboswitches ${ }^{96}$ and RNA-drug complexes. ${ }^{97}$ The nanopore's capability in revealing the pseudoknot unfolding procedure allows investigating the $\mathrm{Mg}^{2+}$ effect on each unfolding step. We found that in the absence of $\mathrm{Mg}^{2+}$, the durations of both Level-1 and Level-2 stages were considerably shortened (Table 3). For 5'-PK, the durations of Level-1 and level- 2 were shortened to $37 \pm 5 \mathrm{~ms}$ and $2.4 \pm 0.6 \mathrm{~ms}$ without $\mathrm{Mg}^{2+}$, compared to $94 \pm 6 \mathrm{~ms}$ and $4.1 \pm 0.3 \mathrm{~ms}$ in $10 \mathrm{mM} \mathrm{Mg}^{2+}$. Similarly, both stage durations for $3^{\prime}-\mathrm{PK}$ were shortened to $210 \pm 25 \mathrm{~ms}$ and $11 \pm 1 \mathrm{~ms}$ in the absence of $\mathrm{Mg}^{2+}$ from $330 \pm 40 \mathrm{~ms}$ and $21 \pm 3 \mathrm{~ms}$ in $10 \mathrm{mM} \mathrm{Mg}^{2+}$. Therefore, $\mathrm{Mg}^{2+}$ can prolong the durations of both stages for unfolding from either direction, suggesting that $\mathrm{Mg}^{2+}$ ions interact with and stabilize both the pseudoknot tertiary structure and its partially unfolded hairpins. This finding seems to be different from the $\mathrm{Mg}^{2+}$ effect on VPK pseudoknot, ${ }^{98}$ in which only one $\mathrm{Mg}^{2+}$ ion was considered to bind in a binding pocket formed by nucleotides in loop 1 and the major groove of stem 2 . 
To detect the pseudoknot unfolding at low salt concentration in near-physiological conditions, we added $140 \mathrm{mM} \mathrm{NaCl}$ in the cis solution in which pseudoknot was presented, and added $2 \mathrm{M} \mathrm{NaCl}$ in the trans solution. Such an asymmetric solution design allows the pseudoknot to be studied in low salt concentration on one side, while the high salt concentration in trans region ensures a high pore conductance needed for distinguishing different blocking levels without influencing the properties of pseudoknot in cis. In addition, the salt gradient across the pore can enhance the capture rate of nucleic acids molecules. ${ }^{72,99}$ We found that both $5^{\prime}$-PK and $3^{\prime}$-PK in $140 \mathrm{mM} \mathrm{NaCl}$ generated the same two-level signatures as in $1 \mathrm{M} \mathrm{NaCl}$ (Figure S8). However, the durations of all blocking levels (Figure S8) in their signatures were shortened compared with high salt concentration (Table 3). For $5^{\prime}$-PK in $140 \mathrm{mM} \mathrm{NaCl}$, the duration of Level-1 and Level-2 stages were shortened to $18 \pm 3$ $\mathrm{ms}$ and $0.81 \pm 0.09 \mathrm{~ms}$, compared with $94 \pm 7 \mathrm{~ms}$ and $4.1 \pm 0.3 \mathrm{~ms}$ in $1 \mathrm{M} \mathrm{NaCl}$. Similarly, low salt concentration reduced $3^{\prime}$-PK's Level-1 and Level-2 durations to $41 \pm 8 \mathrm{~ms}$ and 1.8 $\pm 0.2 \mathrm{~ms}$, compared with $330 \pm 40 \mathrm{~ms}$ and $21 \pm 3 \mathrm{~ms}$ in high salt concentration. Notably, the duration of both levels in $3^{\prime}$-PK and 5'-PK signatures can be fitted into a two-component exponential function as in $1 \mathrm{M} \mathrm{NaCl}$. All these results suggest that, similar to $\mathrm{Mg}^{2+}$, low $\mathrm{Na}^{+}$ concentration can also lower the stability of pseudoknot and its intermediate structures. However, low salt concentration does not change the unfolding pathway of pseudoknot in each direction. Therefore, the unfolding pathways dissected in $1 \mathrm{M} \mathrm{NaCl}$ could be implicated in the living cell environment.

Metal ions can screen the negative charges on nucleic acids and stabilize the folded RNA structures. Divalent $\mathrm{Mg}^{2+}$ ions are more effective compared with monovalent $\mathrm{Na}^{+}$in screening negative charges on nucleic acids. Low $\mathrm{Mg}^{2+}$ concentration may be sufficient to stabilize a compact RNA structure. It has been found that $\mathrm{Mg}^{2+}$ at the millimolar (mM) level can cause similar folding stability as monovalent ion at the molar (M) level. ${ }^{100-102} \mathrm{We}$ identified the similar trend in the unfolding kinetics of T2 pseudoknot. Overall, the pseudoknot stability can be regulated by both divalent $\mathrm{Mg}^{2+}$ and monovalent $\mathrm{Na}^{+}$. This finding suggests a possibility to program the pseudoknot stability by the combined use of multiple metal ions, in order for understanding the ribosomal unfolding of RNA tertiary structure in vivo and RNA-based drug design. ${ }^{103}$

\section{DISCUSSION}

The nanopore's capability in unfolding along the backbone of biopolymer, i.e., vectorial unfolding, may help to reveal different intermediate states and unfolding pathway that is different from the thermodynamic approaches. UV-Vis thermal denaturation experiments reveal essentially identical melting profiles for T2, 3'-PK, 5'-PK, 3'-PK-mut, and 5'-PK-mut (Figure S9). The melting temperatures observed are comparable to those previously reported for the related gene 32 mRNA pseudoknot of bacteriophage T4. ${ }^{89,90}$ Thus, the melting studies indicate that the presence of poly(CAT) 10 extensions on the pseudoknot structures do not alter their thermal stability. This, in turn, suggests that the pseudoknot structures remain unperturbed by the DNA leader. Furthermore, we do not observe significant differences in thermal stability (melting profiles) of pseudoknots containing different nucleobases in the loop regions of L2. Interestingly, pseudoknots containing base substitutions in the loop region do produce distinct signals in the nanopore experiments. This suggests that the 
nanopore has a unique capacity to detect these subtle differences in pseudoknot sequence/ structure. It is possible that interactions of nucleobases in the loop with protein functional groups in the vestibule of the nanopore yield the observed differences in dwell time (or residual current). Alternatively, or in addition, the vectorial unfolding induced by pulling the pseudoknot through the pore may provide a distinct and more sensitive means, compared to thermal denaturation which unfolds globally and has a different unfolding mechanism, for detecting differences in the stability of these folded nucleic acid structures

The nanopore results indicate that the unfolding of the T2 pseudoknot involves two main steps with multiple intermediate states. This observation matches the results from molecular dynamics simulations, ${ }^{21,22,36,37}$ theoretical predictions, ${ }^{20,35,101}$ and thermal melting experiments ${ }^{6,12,32-34,104}$ for other pseudoknots such as T4 RNA and the human telomerase RNA pseudoknot. In combination with theoretical analysis, the nanopore kinetics experiment provided valuable insights into the interplay between the different interactions in RNA pseudoknot unfolding. These interactions include secondary structural interactions such as base pairing and base stacking, and tertiary structural interactions such as coaxial stacking and loop-helix base triple interactions. Unfolding of the pseudoknot involves disruptions of base pairs in the helix, coaxial stacking between helices, and loop-helix base triple contacts. For the sequential unfolding under specific directional pulling in the nanopore, coaxial stacking is broken after the unfolding of a helix. Furthermore, the competition and cooperation of the different interactions led to the different pathways. For the T2 pseudoknot, although the 5-bp H1 is less stable than the 7-bp H2, breaking H1 as the first step in $5^{\prime}$-PK is slower than breaking $\mathrm{H} 2$ as the second step due to the extensive stabilizing tertiary contacts between L2 and H1. Furthermore, comparison with the helixonly duplex system suggested that the kinetic barrier of breaking H1 (in 5'-PK) corresponds to the disruption of the triples, which indicated that the rate-limiting step is the disruption of first few base pairs from the $5^{\prime}$-end that results in a concomitant disruption of the triples. In contrast, for $3^{\prime}$-PK, the unfolding of $\mathrm{H} 1$ (as the second step) is very fast because the unfolding of $\mathrm{H} 2$ (as the first step) cooperatively causes destabilization of L2 and the tertiary contacts between $\mathrm{L} 2$ and $\mathrm{H} 1$.

In addition to the pseudoknot stability and unfolding kinetics, the nanopore signatures can be used to directly identify different structures of the designed chimeras. These structures, their corresponding molecular processes in the nanopore, and their populations are summarized in Figure S6. These T2-RNAs can not only form pseudoknot, but also form partially folded stem-loop hairpins, or adopt the extended conformation in our in vitro condition. The WT pseudoknot populations (T2-PK, $5^{\prime}$-PK and 3-PK) were about 50\%, and the mutation (5'-and $3^{\prime}$-PK-mut) decreased the pseudoknot populations. This population difference is consistent with their mechanical stability difference revealed by the nanopore. The partially folded structures, if verified as a common property for different pseudoknots, may play functional roles such as controlling the frameshift efficiency. ${ }^{28,39,105}$ The nanopore results suggest that pseudoknot-forming RNA molecules may not all fold into the pseudoknot structure. Folded and unfolded RNAs are in equilibrium, and for most retroviruses, probably only the folded RNA can lead to the frameshifting. Therefore, the important follow-up studies can be envisioned to investigate how the in vitro observed 
pseudoknot folding and unfolding efficiency is correlated with their associated in vivo physiology function such as frameshifting.

\section{CONCLUSION AND PERSPECTIVE}

The nanopore single-molecule sensor combined with molecular design enables investigation of the vectorial, stepwise, multi-state unfolding of RNA pseudoknots. The nanopore data provides a direct comparison between the pseudoknot unfolding pathways under different pulling directions. The pulling direction dependent kinetics shows that in either pulling direction, the unfolding is rate-limited by the first step, namely, the disruption of the pseudoknot into a hairpin structure. It is possible that this unfolding step needs to disrupt noncanonical interactions such as triplex and coaxial stacking involved in the stabilization of the global RNA tertiary structure. As verified by the Monte Carlo kinetic simulation, the pseudoknot loop can also contribute to the unfolding rates by either forming new short helix or by adjusting its loop configurations. It could be possible to adapt the nanopore approach to study other RNA pseudoknots and riboswitches, and the unique information collected using this approach may provide new insights into in vivo unfolding mechanisms, gene regulation mechanisms such as frameshifting, ${ }^{106-109}$ and the design of new antiviral drugs.

\section{METHODS}

\section{Chemicals and Nucleic Acids}

All chemicals include $\mathrm{NaCl}, \mathrm{KCl}, \mathrm{MgCl}_{2}, 3$-( $\mathrm{N}$-morpholino) propanesulfonic acid (MOPS), diethylpyrocarbonate (DEPC) were obtained from Sigma-Aldrich (St. Louis, MO, USA) and used as received. Lipid 1,2-diphytanoyl-sn-glycero-3-phosphocholine for bilayer formation was purchased from Avanti Polar Lipids (Alabaster, AL, USA) and used without further purification. DNAs, RNAs and DNA-RNA chimeras used in this study (Table 1) were synthesized by Integrated DNA Technologies Inc. (Coralville, IA).

\section{Pseudoknot Formation}

Synthetic DNA-RNA chimeras were first denatured in DEPC treated water at $95{ }^{\circ} \mathrm{C}$ for 5 min, immediately snap-cooled on ice, and adjusted to $50 \mathrm{mM} \mathrm{NaCl}, 25 \mathrm{mM}$ MOPS (pH 7.4), $10 \mathrm{mM} \mathrm{MgCl}_{2}$ (or without $\mathrm{MgCl}_{2}$ ), or other composition of buffers as mentioned in the electrophysiology measurements and then either kept on ice or prewarmed at $37.5^{\circ} \mathrm{C}$ for $3 \mathrm{~h}$ before electrophysiology measurement.

\section{Single Protein Pore Formation, Current Recording and Event Analysis}

Lipid bilayer composed of 1,2-diphytanoyl-sn-glycero-3-phosphocholine was formed on a $\sim 150 \mu \mathrm{m}$ orifice in a Teflon film that separates two Teflon chambers. For symmetric solution, each chamber contains $2 \mathrm{~mL}$ of solution containing $1 \mathrm{M} \mathrm{NaCl}, 10 \mathrm{mM} \mathrm{MgCl}_{2}$ and $25 \mathrm{mM}$ MOPS (pH 7.4). For near-physiological experiments (asymmetric solutions), cis chamber was added with $140 \mathrm{mM} \mathrm{NaCl}, 5 \mathrm{mM} \mathrm{KCl}, 1 \mathrm{mM} \mathrm{CaCl}_{2}, 0-10 \mathrm{mM} \mathrm{MgCl}_{2}$, and 25 $\mathrm{mM}$ MOPS (pH 7.4), and trans chamber with $2 \mathrm{M} \mathrm{NaCl}, 0-10 \mathrm{mM} \mathrm{MgCl}_{2}$, and $25 \mathrm{mM}$ MOPS (pH 7.4). The concentration of all chimeras in the nanopore experiments was 100 $\mathrm{nM}$. The concentration of T2-PK was $300 \mathrm{nM}$. $1-5 \mu \mathrm{L}$ of a-hemolysin solution was added to 
the cis chamber to form single protein pores in the lipid bilayer membrane from the cis side. The ionic current through the pore was recorded using an Axopatch 200B amplifier (Molecular Devices Inc., Sunnyvale, CA). The amplified signal was filtered with a built-in 4-pole low-pass Bessel Filter at $5 \mathrm{kHz}$ before acquired into the computer using a DigiData 1440A A/D converter (Molecular Devices) at a sampling rate of $20 \mathrm{kHz}$. The data recording and acquisition were controlled through a Clampex program (Molecular Devices) and nanopore current traces were analyzed using a Clampfit 10.4 software (Molecular Devices). Because the two-level pseudoknot unfolding signatures are distinguished from other types of blocks (Figure S6), there was no need to set cutoff for analyzing the signature duration and current amplitude. The duration of each current level (Level-1 and Level-2) in a signature was measured by two cursors in the software from the beginning to the end of the level. The duration values for all signatures were collected to construct histograms. The duration distribution was fitted with a two-exponential function (Figure S10) to obtain the durations of two intermediate states $\tau_{1}$ and $\tau_{2}$. Their sum $\left(\tau_{1}+\tau_{2}\right)$ yielded the mean duration $\tau$ of Level-1 or Level-2. The duration values from at least three experiments $(n \geq 3)$ with independent nanopores were used to obtain the mean $\tau$, and its standard deviation (SD). The residual currents were obtained by fitting the event current amplitude histogram using Gaussian function in Clampfit. The standard deviation for each result value was based on at least three independent experiments. All nanopore pulling experiments were conducted at room temperature $22 \pm 1{ }^{\circ} \mathrm{C}$.

\section{Melting Temperature Measurement}

The melting temperatures of T2 RNA pseudoknot and its derivatives were determined by monitoring the increase in absorbance at $260 \mathrm{~nm}$ as a function of temperature. The temperature was increased from 22 to $95^{\circ} \mathrm{C}$ at a rate of $0.5{ }^{\circ} \mathrm{C} / \mathrm{min}$. The melting temperature was determined using Cary WinUV-Thermal software. The first derivative of each smoothed absorbance curve with respect to temperature was calculated $(\partial A / \partial T)$, and normalized by dividing the derivative value by the absorbance at $90{ }^{\circ} \mathrm{C}$ (ref 104).

\section{Supplementary Material}

Refer to Web version on PubMed Central for supplementary material.

\section{Acknowledgments}

We are grateful to the National Institutes of Health for support of this work through initial R01-GM079613 (L.Q.G.) and current R01-GM114204 (L.Q.G.), R01-GM063732 (S.J.C.), and ES021007 (K.S.G.).

\section{REFERENCES}

1. Cruz JA, Westhof E. Cell. 2009; 136:604. [PubMed: 19239882]

2. Gleitsman KR, Herschlag DH. RNA. 2014; 20:1732. [PubMed: 25246656]

3. Lee JT. Science. 2012; 338:1435. [PubMed: 23239728]

4. Mandal M, Breaker RR. Nat. Rev. Mol. Cell Biol. 2004; 5:451. [PubMed: 15173824]

5. Mortimer SA, Kidwell MA, Doudna JA. Nat. Rev. Genet. 2014; 15:469. [PubMed: 24821474]

6. Theimer CA, Feigon J. Curr. Opin. Struct. Biol. 2006; 16:307. [PubMed: 16713250] 
7. Belew AT, Meskauskas A, Musalgaonkar S, Advani VM, Sulima SO, Kasprzak WK, Shapiro BA, Dinman JD. Nature. 2014; 512:265. [PubMed: 25043019]

8. Chen JL, Greider CW. Proc. Natl. Acad. Sci. U. S. A. 2005; 102:8080. [PubMed: 15849264]

9. Hashem Y, des Georges A, Dhote V, Langlois R, Liao HY, Grassucci RA, Pestova TV, Hellen CU, Frank J. Nature. 2013; 503:539. [PubMed: 24185006]

10. Narayanan R, Velmurugu Y, Kuznetsov SV, Ansari A. J. Am. Chem. Soc. 2011; 133:18767. [PubMed: 21958201]

11. Plant EP, Perez-Alvarado GC, Jacobs JL, Mukhopadhyay B, Hennig M, Dinman JD. PLoS Biol. 2005; 3:e172. [PubMed: 15884978]

12. Staple DW, Butcher SE. PLoS Biol. 2005; 3:e213. [PubMed: 15941360]

13. Theimer CA, Blois CA, Feigon J. Mol. Cell. 2005; 17:671. [PubMed: 15749017]

14. Tuerk C, MacDougal S, Gold L. Proc. Natl. Acad. Sci. U. S. A. 1992; 89:6988. [PubMed: 1379730]

15. Zhang L, Bao P, Leibowitz MJ, Zhang Y. RNA. 2009; 15:1986. [PubMed: 19710184]

16. Herschlag D. RNA. 2015; 21:527. [PubMed: 25780124]

17. Serganov A, Patel DJ. Nat. Rev. Genet. 2007; 8:776. [PubMed: 17846637]

18. Morris KV, Mattick JS. Nat. Rev. Genet. 2014; 15:423. [PubMed: 24776770]

19. Rinn JL, Chang HY. Annu. Rev. Biochem. 2012; 81:145. [PubMed: 22663078]

20. Cao S, Giedroc DP, Chen SJ. RNA. 2010; 16:538. [PubMed: 20100813]

21. Cho SS, Pincus DL, Thirumalai D. Proc. Natl. Acad. Sci. U. S. A. 2009; 106:17349. [PubMed: 19805055]

22. Biyun S, Cho SS, Thirumalai D. J. Am. Chem. Soc. 2011; 133:20634. [PubMed: 22082261]

23. Peselis A, Serganov A. Wiley interdisciplinary reviews. RNA. 2014; 5:803. [PubMed: 25044223]

24. Brierley I, Pennell S, Gilbert RJ. Nat. Rev. Microbiol. 2007; 5:598. [PubMed: 17632571]

25. Cao S, Chen SJ. Phys. Biol. 2008; 5:016002. [PubMed: 18367782]

26. Farabaugh PJ. Annu. Rev. Genet. 1996; 30:507. [PubMed: 8982463]

27. Blount KF, Breaker RR. Nat. Biotechnol. 2006; 24:1558. [PubMed: 17160062]

28. Brierley I, Digard P, Inglis SC. Cell. 1989; 57:537. [PubMed: 2720781]

29. Loh E, Dussurget O, Gripenland J, Vaitkevicius K, Tiensuu T, Mandin P, Repoila F, Buchrieser C, Cossart P, Johansson J. Cell. 2009; 139:770. [PubMed: 19914169]

30. Tucker BJ, Breaker RR. Curr. Opin. Struct. Biol. 2005; 15:342. [PubMed: 15919195]

31. Verhounig A, Karcher D, Bock R. Proc. Natl. Acad. Sci. U. S. A. 2010; 107:6204. [PubMed: 20308585]

32. Gluick TC, Draper DE. J. Mol. Biol. 1994; 241:246. [PubMed: 7520082]

33. Soto AM, Misra V, Draper DE. Biochemistry. 2007; 46:2973. [PubMed: 17315982]

34. Nixon PL, Giedroc DP. Biochemistry. 1998; 37:16116. [PubMed: 9819204]

35. Cao S, Chen SJ. RNA. 2009; 15:696. [PubMed: 19237463]

36. Yingling YG, Shapiro BA. J. Mol. Graphics Modell. 2006; 25:261.

37. Zhang Y, Zhang J, Wang W. J. Am. Chem. Soc. 2011; 133:6882. [PubMed: 21500824]

38. Cornish PV, Hennig M, Giedroc DP. Proc. Natl. Acad. Sci. U. S. A. 2005; 102:12694. [PubMed: 16123125]

39. Giedroc DP, Theimer CA, Nixon PL. J. Mol. Biol. 2000; 298:167. [PubMed: 10764589]

40. Cecconi C, Shank EA, Bustamante C, Marqusee S. Science. 2005; 309:2057. [PubMed: 16179479]

41. Dudko OK, Hummer G, Szabo A. Proc. Natl. Acad. Sci. U. S. A. 2008; 105:15755. [PubMed: 18852468]

42. Greenleaf WJ, Frieda KL, Foster DA, Woodside MT, Block SM. Science. 2008; 319:630. [PubMed: 18174398]

43. Kellermayer MS, Smith SB, Granzier HL, Bustamante C. Science. 1997; 276:1112. [PubMed: 9148805]

44. Liphardt J, Onoa B, Smith SB, Tinoco I Jr, Bustamante C. Science. 2001; 292:733. [PubMed: 11326101]

J Am Chem Soc. Author manuscript; available in PMC 2016 May 31. 
45. Rief M, Gautel M, Oesterhelt F, Fernandez JM, Gaub HE. Science. 1997; 276:1109. [PubMed: 9148804]

46. Chen G, Wen JD, Tinoco I Jr. RNA. 2007; 13:2175. [PubMed: 17959928]

47. Tinoco I Jr, Li PT, Bustamante C. Q. Rev. Biophys. 2006; 39:325. [PubMed: 17040613]

48. Green L, Kim CH, Bustamante C, Tinoco I Jr. J. Mol. Biol. 2008; 375:511. [PubMed: 18021801]

49. Cao S, Chen SJ. J. Mol. Biol. 2007; 367:909. [PubMed: 17276459]

50. Yagawa K, Yamano K, Oguro T, Maeda M, Sato T, Momose T, Kawano S, Endo T. Protein science: a publication of the Protein Society. 2010; 19:693. [PubMed: 20095049]

51. Song L, Hobaugh MR, Shustak C, Cheley S, Bayley H, Gouaux JE. Science. 1996; 274:1859. [PubMed: 8943190]

52. Kasianowicz JJ, Brandin E, Branton D, Deamer DW. Proc. Natl. Acad. Sci. U. S. A. 1996; 93:13770. [PubMed: 8943010]

53. Shim J, Gu LQ. Methods. 2012; 57:40. [PubMed: 22487183]

54. Shim JW, Gu LQ. J. Phys. Chem. B. 2008; 112:8354. [PubMed: 18563930]

55. An N, Fleming AM, Middleton EG, Burrows CJ. Proc. Natl. Acad. Sci. U. S. A. 2014; 111:14325. [PubMed: 25225404]

56. Akeson M, Branton D, Kasianowicz JJ, Brandin E, Deamer DW. Biophys. J. 1999; 77:3227. [PubMed: 10585944]

57. Butler TZ, Gundlach JH, Troll M. Biophys. J. 2007; 93:3229. [PubMed: 17675346]

58. Butler TZ, Gundlach JH, Troll MA. Biophys. J. 2006; 90:190. [PubMed: 16214857]

59. Clamer M, Höfler L, Mikhailova E, Viero G, Bayley H. ACS Nano. 2014; 8:1364. [PubMed: 24369707]

60. Cracknell JA, Japrung D, Bayley H. Nano Lett. 2013; 13:2500. [PubMed: 23678965]

61. Japrung D, Henricus M, Li Q, Maglia G, Bayley H. Biophys. J. 2010; 98:1856. [PubMed: 20441749]

62. Smith AM, AbuShumays RL, Akeson M, Bernick DL. Front. Bioeng. Biotechnol. 2015

63. Laszlo AH, Derrington IM, Ross BC, Brinkerhoff H, Adey A, Nova IC, Craig JM, Langford KW, Samson JM, Daza R, Doering K, Shendure J, Gundlach JH. Nat. Biotechnol. 2014; 32:829. [PubMed: 24964173]

64. Olasagasti F, Lieberman KR, Benner S, Cherf GM, Dahl JM, Deamer DW, Akeson M. Nat. Nanotechnol. 2010; 5:798. [PubMed: 20871614]

65. Hornblower B, Coombs A, Whitaker RD, Kolomeisky A, Picone SJ, Meller A, Akeson M. Nat. Methods. 2007; 4:315. [PubMed: 17339846]

66. Rodriguez-Larrea D, Bayley H. Nat. Nanotechnol. 2013; 8:288. [PubMed: 23474543]

67. Rodriguez-Larrea D, Bayley H. Nat. Commun. 2014; 5:4841. [PubMed: 25197784]

68. Mathe J, Visram H, Viasnoff V, Rabin Y, Meller A. Biophys. J. 2004; 87:3205. [PubMed: 15347593]

69. Sauer-Budge AF, Nyamwanda JA, Lubensky DK, Branton D. Phys. Rev. Lett. 2003; 90:238101. [PubMed: 12857290]

70. An N, Fleming AM, White HS, Burrows CJ. ACS Nano. 2015; 9:4296. [PubMed: 25768204]

71. Zhang X, Wang Y, Fricke BL, Gu LQ. ACS Nano. 2014; 8:3444. [PubMed: 24654890]

72. Wang Y, Zheng D, Tan Q, Wang MX, Gu LQ. Nat. Nanotechnol. 2011; 6:668. [PubMed: 21892163]

73. Dudko, OK.; Mathé, J.; Meller, A. Methods in Enzymology. Nils, GW., editor. Vol. 475. Academic Press; 2010. p. 565

74. Dudko OK, Mathe J, Szabo A, Meller A, Hummer G. Biophys. J. 2007; 92:4188. [PubMed: 17384066]

75. Lin J, Fabian M, Sonenberg N, Meller A. Biophys. J. 2012; 102:1427. [PubMed: 22455926]

76. Holland JA, Hansen MR, Du Z, Hoffman DW. RNA. 1999; 5:257. [PubMed: 10024177]

77. Wang Y, Tian K, Hunter LL, Ritzo B, Gu LQ. Nanoscale. 2014; 6:11372. [PubMed: 25144935] 
78. Kang I, Wang Y, Reagan C, Fu Y, Wang MX, Gu LQ. Sci. Rep. 2013; 3:2381. [PubMed: 24135881]

79. Mathe J, Aksimentiev A, Nelson DR, Schulten K, Meller A. Proc. Natl. Acad. Sci. U. S. A. 2005; 102:12377. [PubMed: 16113083]

80. Maglia G, Restrepo MR, Mikhailova E, Bayley H. Proc. Natl. Acad. Sci. U. S. A. 2008; 105:19720. [PubMed: 19060213]

81. Ding Y, Fleming AM, White HS, Burrows CJ. J. Phys. Chem. B. 2014; 118:12873. [PubMed: 25333648]

82. Brown JA, Valenstein ML, Yario TA, Tycowski KT, Steitz JA. Proc. Natl. Acad. Sci. U. S. A. 2012; 109:19202. [PubMed: 23129630]

83. Butcher SE, Pyle AM. Acc. Chem. Res. 2011; 44:1302. [PubMed: 21899297]

84. Cash DD, Cohen-Zontag O, Kim N-K, Shefer K, Brown Y, Ulyanov NB, Tzfati Y, Feigon J. Proc. Natl. Acad. Sci. U. S. A. 2013; 110:10970. [PubMed: 23776224]

85. Chauhan S, Woodson SA. J. Am. Chem. Soc. 2008; 130:1296. [PubMed: 18179212]

86. Liu F, Theimer CA. J. Mol. Biol. 2012; 423:719. [PubMed: 22954661]

87. Nixon PL, Cornish PV, Suram SV, Giedroc DP. Biochemistry. 2002; 41:10665. [PubMed: 12186552]

88. Zhou Y, Kierzek E, Loo ZP, Antonio M, Yau YH, Chuah YW, Geifman-Shochat S, Kierzek R, Chen G. Nucleic Acids Res. 2013; 41:6664. [PubMed: 23658228]

89. Seol Y, Skinner GM, Visscher K. Phys. Rev. Lett. 2004; 93:118102. [PubMed: 15447383]

90. Seol Y, Skinner GM, Visscher K, Buhot A, Halperin A. Phys. Rev. Lett. 2007; 98:158103. [PubMed: 17501388]

91. Xu X, Chen S-J. J. Am. Chem. Soc. 2012; 134:12499. [PubMed: 22765263]

92. Cao S, Chen S-J. Biophys. J. 2009; 96:4024. [PubMed: 19450474]

93. Metropolis N, Rosenbluth AW, Rosenbluth MN, Teller AH, Teller E. J. Chem. Phys. 1953; 21:1087.

94. Cocco S, Marko JF, Monasson R. Eur. Phys. J. E: Soft Matter Biol. Phys. 2003; 10:153.

95. Xu X, Zhao P, Chen S-J. PLoS One. 2014; 9:e107504. [PubMed: 25215508]

96. Hayes RL, Noel JK, Mohanty U, Whitford PC, Hennelly SP, Onuchic JN, Sanbonmatsu KY. J. Am. Chem. Soc. 2012; 134:12043. [PubMed: 22612276]

97. Hermann T. Angew. Chem., Int. Ed. 2000; 39:1890.

98. Gonzalez RL Jr, Tinoco I Jr. J. Mol. Biol. 1999; 289:1267. [PubMed: 10373367]

99. Wanunu M, Morrison W, Rabin Y, Grosberg AY, Meller A. Nat. Nanotechnol. 2010; 5:160. [PubMed: 20023645]

100. Bai Y, Chu VB, Lipfert J, Pande VS, Herschlag D, Doniach S. J. Am. Chem. Soc. 2008; 130:12334. [PubMed: 18722445]

101. Chen SJ. Annu. Rev. Biophys. 2008; 37:197. [PubMed: 18573079]

102. Draper DE. Biophys. J. 2008; 95:5489. [PubMed: 18835912]

103. Dinman JD, Ruiz-Echevarria MJ, Peltz SW. Trends Biotechnol. 1998; 16:190. [PubMed: 9586242]

104. Qiu H, Kaluarachchi K, Du Z, Hoffman DW, Giedroc DP. Biochemistry. 1996; 35:4176. [PubMed: 8672454]

105. Draper DE. Curr. Opin. Cell Biol. 1990; 2:1099. [PubMed: 2099803]

106. Dulude D, Baril M, Brakier-Gingras L. Nucleic Acids Res. 2002; 30:5094. [PubMed: 12466532]

107. Kontos H, Napthine S, Brierley I. Molecular and cellular biology. 2001; 21:8657. [PubMed: 11713298]

108. Plant EP, Jacobs KL, Harger JW, Meskauskas A, Jacobs JL, Baxter JL, Petrov AN, Dinman JD. RNA. 2003; 9:168. [PubMed: 12554858]

109. Staple DW, Butcher SE. J. Mol. Biol. 2005; 349:1011. [PubMed: 15927637]

110. Yang H, Jossinet F, Leontis N, Chen L, Westbrook J, Berman H, Westhof E. Nucleic Acids Res. 2003; 31:3450. [PubMed: 12824344] 
111. Xie S. Single Mol. 2001; 2:229. 
a

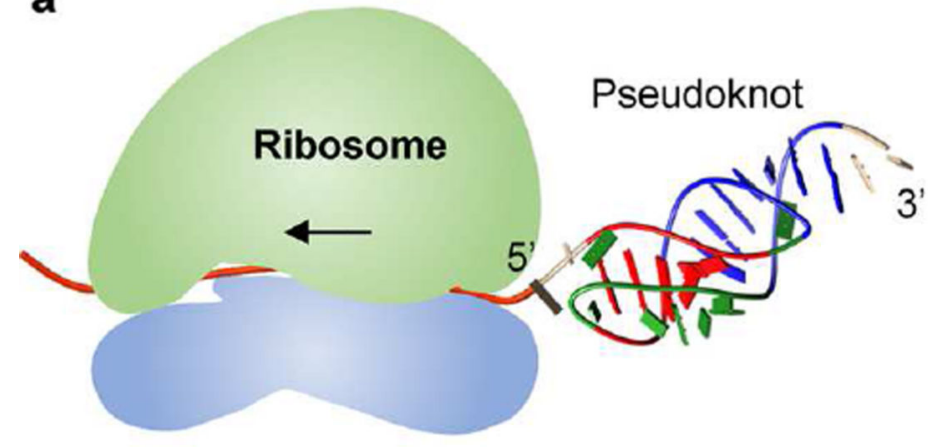

b

$1^{\text {st }}$ Helix stem

Non-canonical

interactions

Figure 1. helices are illustrated. d

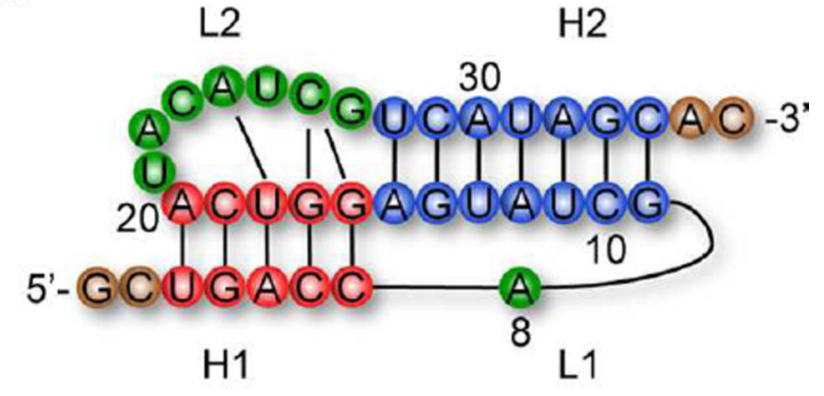

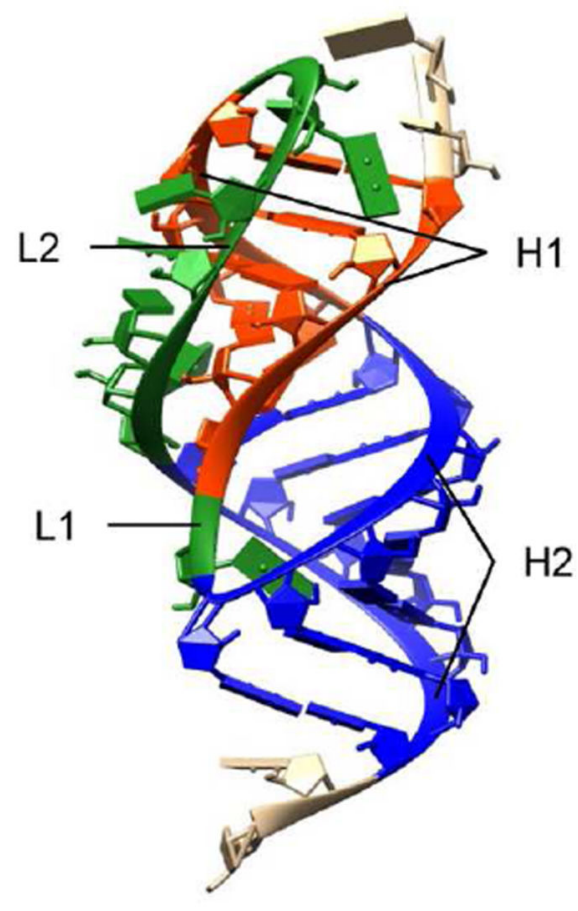

Mimicking ribosomal unfolding of RNA pseudoknot in a protein nanopore. (a,b) Cartoons showing the unfolding of a downstream pseudoknot as ribosome slides on mRNA from the $5^{\prime}$ to $3^{\prime}$ end for protein expression (a), and vectorial unfolding of a tagged-pseudoknot in the a-hemolysin protein channel (b). (c) Current signature in response to the unfolding of a pseudoknot in the nanopore, with distinct blocking levels revealing the unfolding sequence of different parts in the pseudoknot. (d) 2D and 3D structures of the RNA pseudoknot located at the $5^{\prime}$ end of the gene $32 \mathrm{mRNA}$ of bacteriophage T2 (PDB id: 2tpk), which contains two helices, H1 (red, U3-C7:G16-A20) and H2 (blue, G9-A15:U28-C34), ${ }^{76}$ and two loops (green), L1 (A8) and L2 (U21-G27). The base triple interactions between loops and helices (identified by RNAview ${ }^{110}$ ) in magenta and the coaxial stacking between two 
a

5'-PK

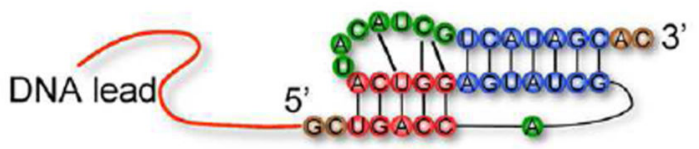

3'-PK

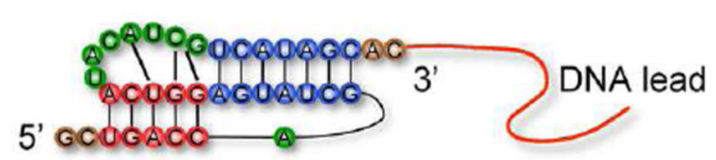

b

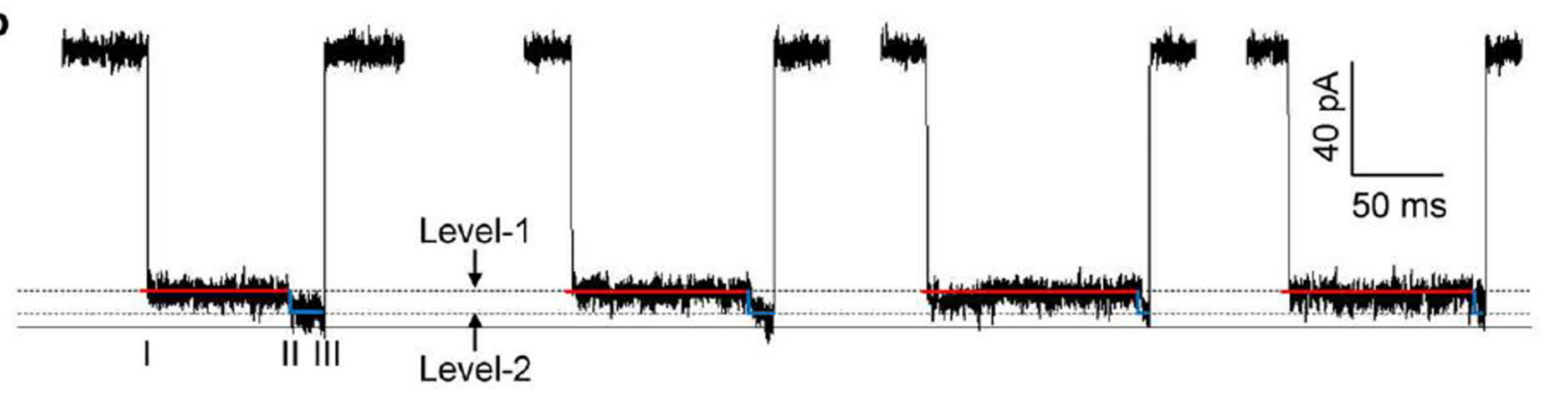

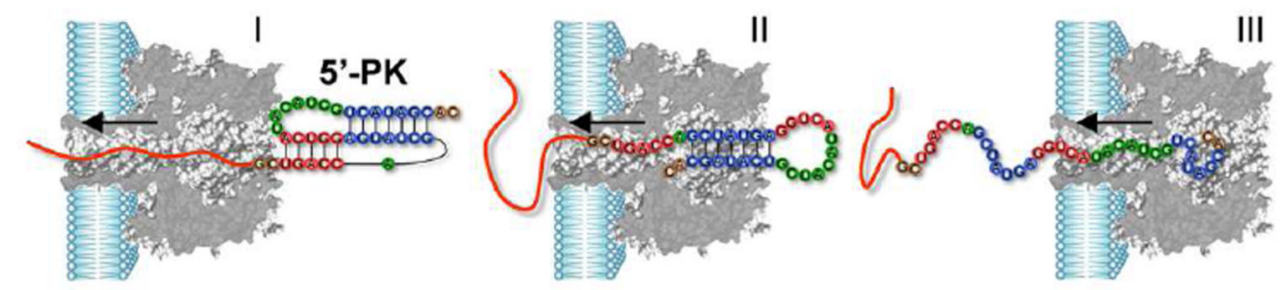

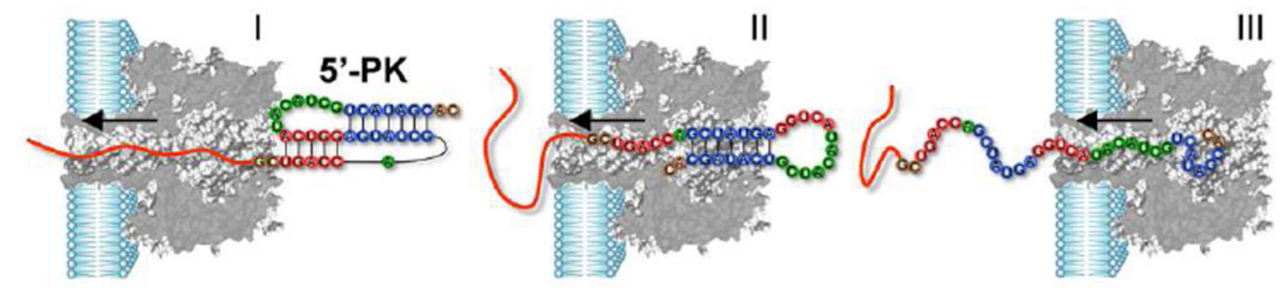

III

C
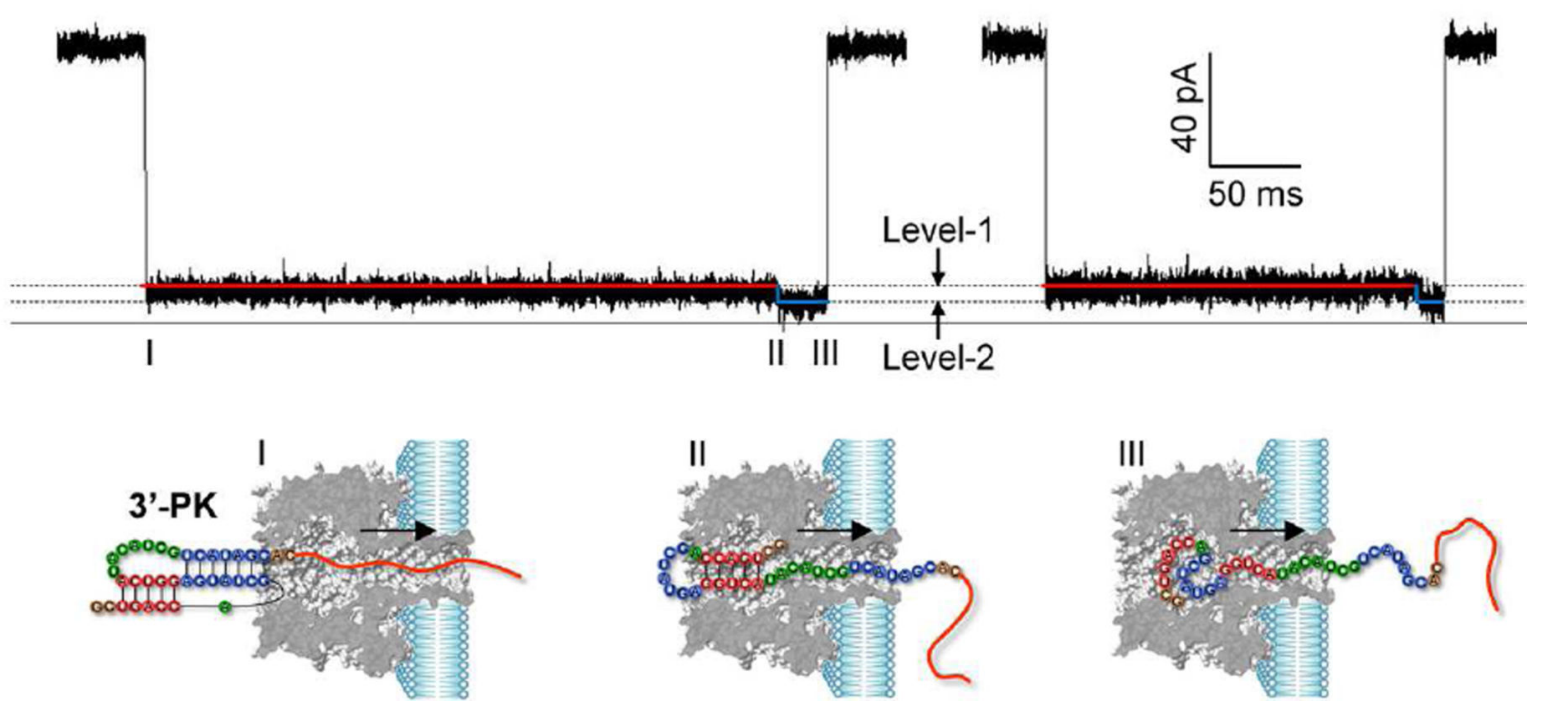

Figure 2.

Nanopore signatures revealing vectorial unfolding procedure of T2 pseudoknot. (a)

Construction of DNA-tagged pseudoknot chimeras. A poly(CAT) 10 ssDNA is attached to the $5^{\prime}$ end $\left(5^{\prime}-\mathrm{PK}\right)$ and $3^{\prime}$ end $\left(3^{\prime}-\mathrm{PK}\right)$ of $\mathrm{T} 2$ pseudoknot for trapping the molecule into the pore and drive its unfolding. (b,c) Representative two-level signatures (Level-1 and Level-2) for stepwise unfolding of $5^{\prime}-\mathrm{PK}$ from $\mathrm{H} 1$ at $5^{\prime}$ end to $\mathrm{H} 2$ at $3^{\prime}$ end (b), and $3^{\prime}-\mathrm{PK}$ from $\mathrm{H} 2$ at $3^{\prime}$ end to $\mathrm{H} 1$ at $5^{\prime}$ end (c). Models below the current traces illustrate the suggested molecular configurations of 5'-PK (b) and 3'-PK (c) for each unfolding step. The nanopore currents 
were recorded at $+120 \mathrm{mV}$ in $1 \mathrm{M} \mathrm{NaCl}$ and $10 \mathrm{mM} \mathrm{MgCl}_{2}$ buffered with $25 \mathrm{mM}$ MOPS (pH 7.4). 


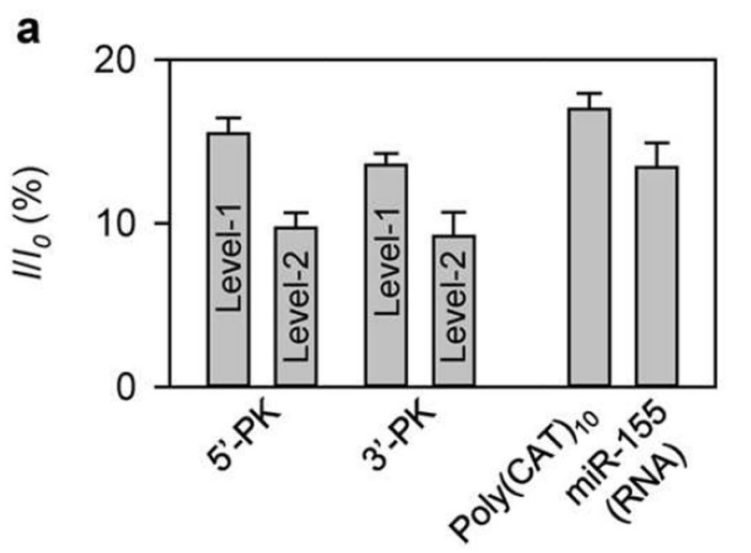

b

a

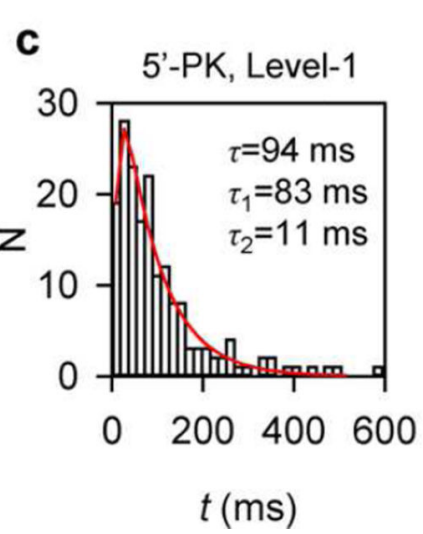

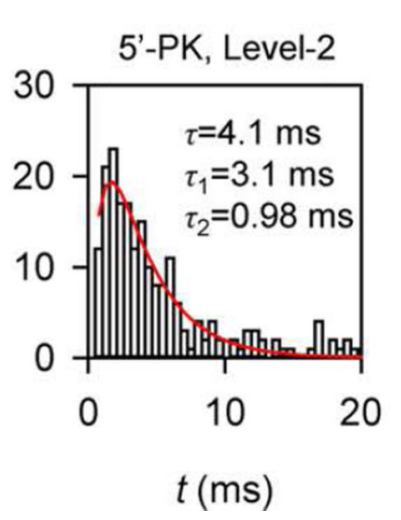

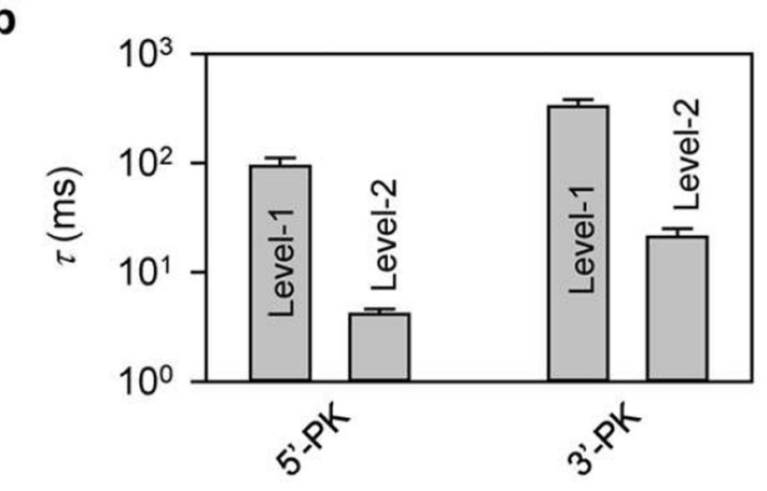

Figure 3.

Characteristic blocking levels and durations of different steps in signatures of pseudoknots and control oligonucleotides. (a) Relative conductance $\left(I / I_{0}, I\right.$ and $I_{0}$ are current amplitudes of the block and empty pore) of Level-1 and Level-2 blocks in the 5'-PK and 3'PK signatures shown in Figure $2 \mathrm{~b}$ and $\mathrm{c}$, and blocks generated by DNA Poly(CAT) 10 and RNA miR-155 translocation through the pore. Blocks of Poly(CAT) 10 and miR-155 were analyzed in Figure S3. (b) Durations of Level-1 and Level-2 stages in the 5'-PK and 3'-PK signatures. (c,d) Representative histograms of Level-1 (left) and Level-2 (right) durations for 5'-PK ( $N$ $=245)(\mathrm{c})$ and $3^{\prime}-\mathrm{PK}(N=272)(\mathrm{d})$. The duration distributions in histograms were fitted with $N(t)=A /\left(\tau_{1}-\tau_{2}\right)\left[e^{-1 t / \tau 1}-e^{-t / \tau_{2}}\right]$, based on a two-step kinetic pathway ${ }^{111}$ (see Figure S10 for the fitting method). The duration of each level $\tau$ was the sum of fitted $\tau_{1}$ and $\tau_{2}$. 
a

d

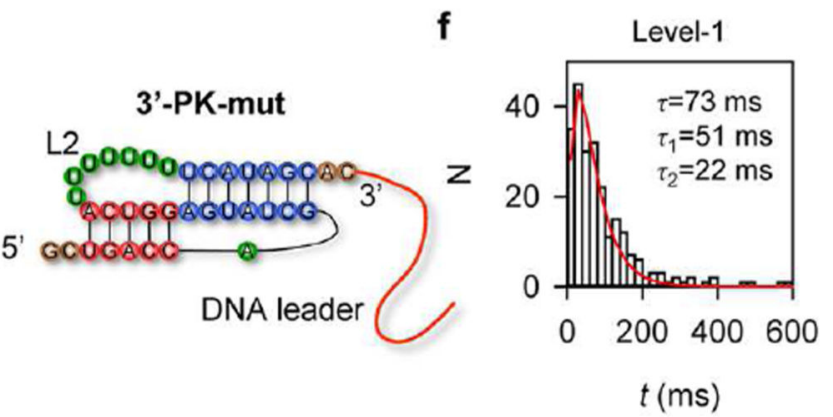

c

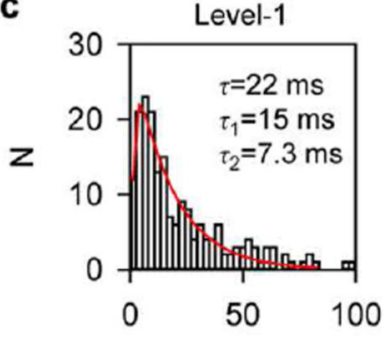

b

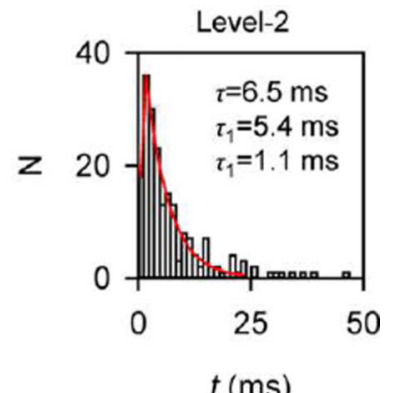

$t(\mathrm{~ms})$
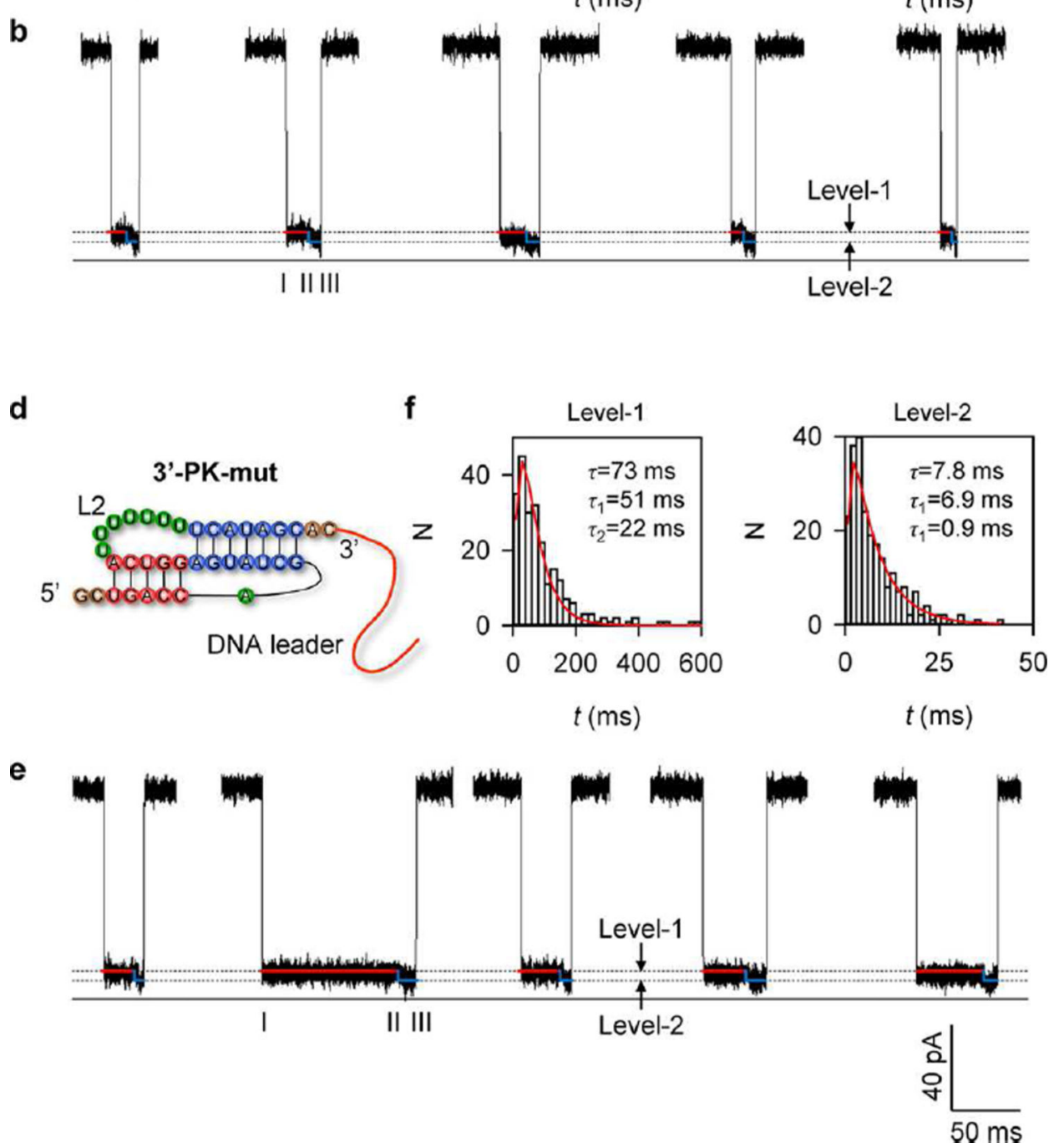

Figure 4.

Unfolding of 5'- and 3'-PK-mut in the nanopore. (a) 2D structure of 5'-PK-mut, with L2 changed to poly(U). (b) Representative two-level signatures (Level-1 and Level-2) for stepwise unfolding of 5'-PK-mut from $\mathrm{H} 1$ at $5^{\prime}$ end to $\mathrm{H} 2$ at $3^{\prime}$ end. (c) Representative histograms of Level-1 (left) and level-2 (right) durations $(N=252)$, which were both fitted with a two-step exponential distribution as 5'-PK in Figure 3. (d) 2D structure of 3'-PK-mut. (e) Representative two-level signatures (Level-1 and Level-2) for stepwise unfolding of 3'PK-mut from $\mathrm{H} 2$ at $3^{\prime}$ end to $\mathrm{H} 1$ at $5^{\prime}$ end. (f) Representative histograms of Level-1 (left) 
and Level-2 (right) durations $(N=239)$ and the two-step exponential fitting as $3^{\prime}-\mathrm{PK}$ in Figure 3. 


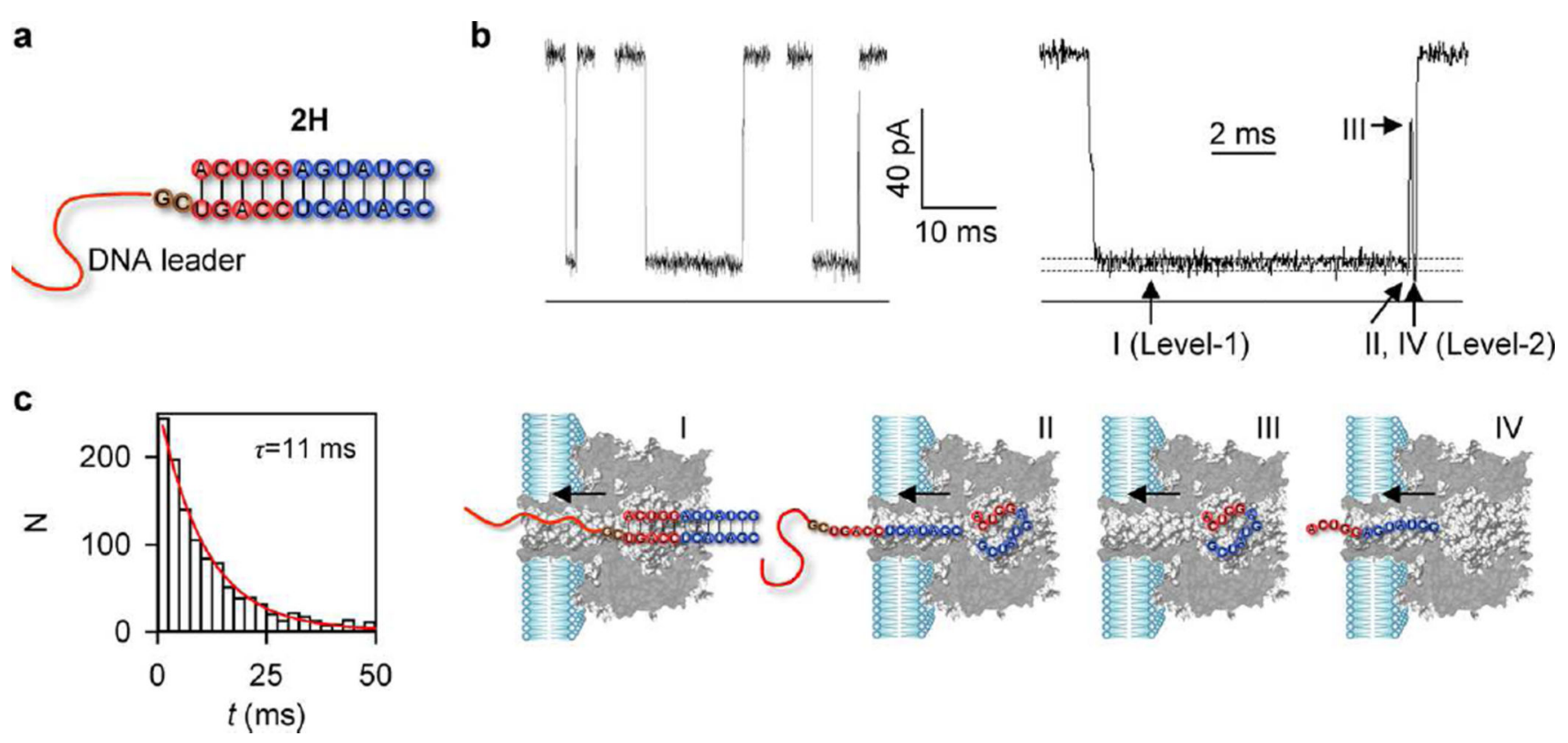

Figure 5.

Unzipping of the RNA duplex $2 \mathrm{H}$ in the nanopore. (a) Structure of $2 \mathrm{H}$, a poly $(\mathrm{CAT})_{10^{-}}$ tagged, truncated pseudoknot that only retains the 5-bp H1 (red) and 7-bp H2 (blue) but without loops. (b) Representative multilevel blocking signatures for $2 \mathrm{H}$ (left) and an expanded signature (right) showing RNA unzipping and translocation as in the model below the traces: I, trapping the DNA leader in the pore (Level-1, $I / I_{0}=14.9 \pm 1.2 \%$ ); II, unzipping of $2 \mathrm{H}$ at the end of Level-1 stage followed by RNA translocation (Level-2, $I / I_{0}=9.7$ $\pm 1.1 \%$ ); III, intermediate partial block for the complementary RNA strand residing in the nanocavity $\left(I / I_{0}=52 \pm 1.9 \%\right)$; and IV, the terminal Level-2 resistive pulse $\left(I / I_{0}=9.6\right.$ $\pm 1.2 \%$ ) for translocation of the complementary RNA strand. Level-2 was lower than Level-1, in consistence with the translocation of DNA followed by RNA in the pseudoknot signatures (Figure $2 \mathrm{~b}$ and c). (c) Duration histograms for the $2 \mathrm{H}$ signatures, fitted with a single-exponential distribution. 


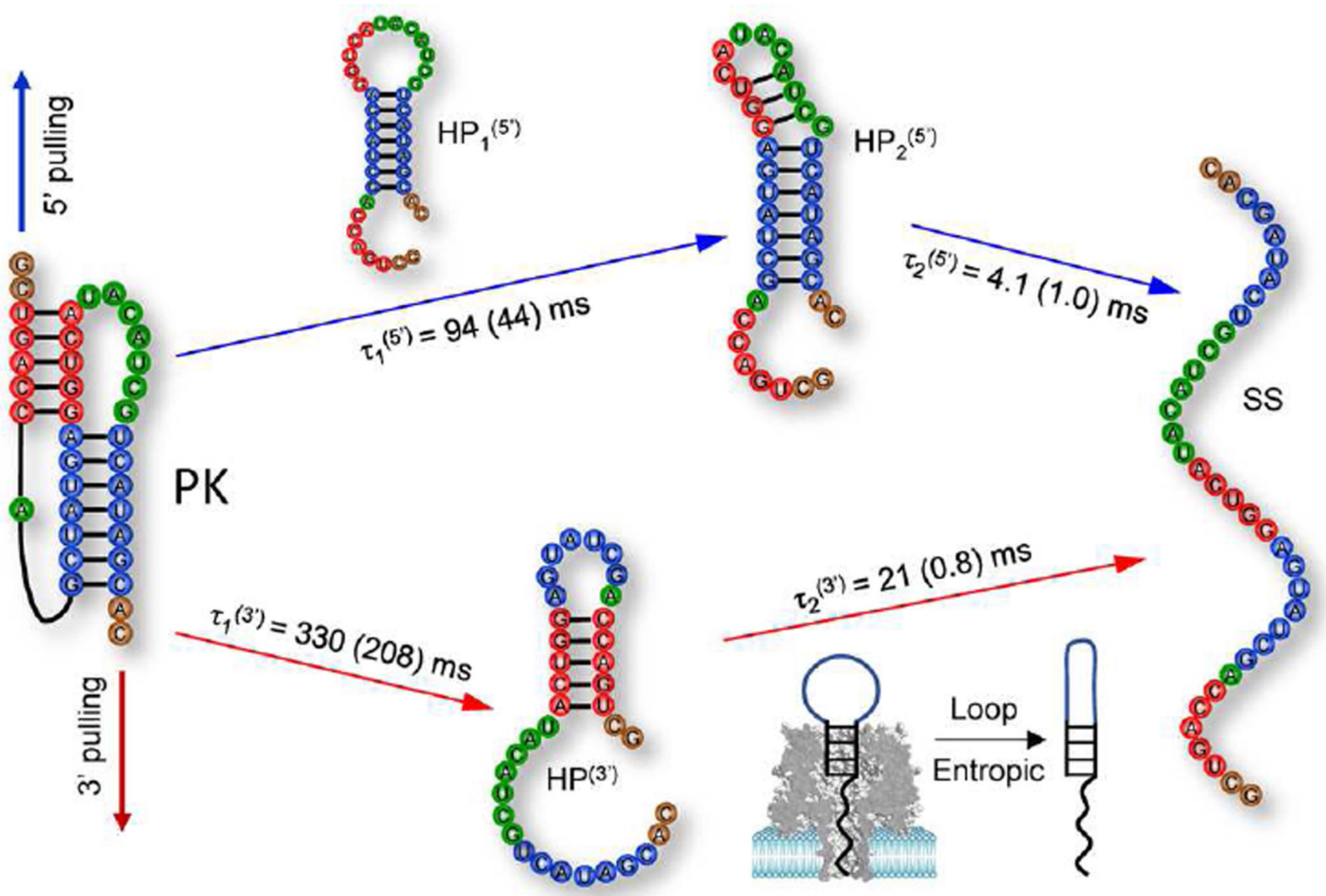

Figure 6.

Predicted pathways of the nanopore unfolding of the T2 pseudoknot for the pulling from the $5^{\prime}$ end (blue) and from the $3^{\prime}$ end (red), respectively. Experimental dwell times and the mean first passage times (FPT) from KMC simulations (in parentheses) for the different steps are shown for comparison. The large difference of $\tau_{2}{ }^{\left(3^{\prime}\right)}(11 \mathrm{~ms}$ vs $0.8 \mathrm{~ms})$ may be accounted for by the pausing time for the 8-nt loop in hairpin $\mathrm{HP}^{\left(3^{\prime}\right)}$ to overcome (mainly entropic) kinetic barrier to form compact conformations so $\mathrm{HP}^{\left(3^{\prime}\right)}$ can pass through the cis opening of the nanopore. In our model, we used $g(V)=1.8 \mathrm{kcal} \mathrm{mol}^{-1}$. Assuming $g(V)=-Q_{\mathrm{eff}} \cdot V$ as the electric potential-induced reduction in the energy barrier with $V=120 \mathrm{mV}$ for the potential drop across the nanopore in the experimental setup, we found the effective net charge $Q_{\text {eff }} \approx$ $0.7 e$ for the chain inside the pore. ${ }^{68}$ Noted that $Q_{\text {eff }}$ is sensitive to the molecular types and the solution conditions, such as ion concentrations and $\mathrm{pH}$ value. 


\section{Table 1}

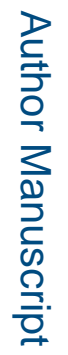

Sequences of Nucleic Acids Used in This Study

\begin{tabular}{|c|c|}
\hline Nucleic acids & Sequence \\
\hline $\mathbf{5}^{\prime}$-PK & $5^{\prime}-(\mathrm{CAT})_{10}$-gcugaccagcuaugaggucauacaucgucauagcac-3' \\
\hline $3^{\prime}$-PK & $5^{\prime}$-gcugaccagcuaugaggucauacaucgucauagcac- $(\mathrm{CAT})_{10}-3^{\prime}$ \\
\hline T2-PK & $5^{\prime}$-gcugaccagcuaugaggucauacaucgucauagcac-3' \\
\hline 5'-PK-mut & $5^{\prime}-(\mathrm{CAT})_{10}$-gcugaccagcuaugaggucauuuuuuuucauagcac- $3^{\prime}$ \\
\hline 3'-PK-mut & $5^{\prime}$-gcugaccagcuaugaggucauuuuuuuucauagcac- $(\mathrm{CAT})_{10}-3^{\prime}$ \\
\hline $2 \mathbf{H}$ & $\begin{array}{c}5^{\prime}-(\mathrm{CAT})_{10}-\text { gcugaccucauagc }^{\prime} 3^{\prime} \\
|||||||||||| \mid \\
3^{\prime} \text {-acuggaguaucg }-5^{\prime}\end{array}$ \\
\hline $\operatorname{Poly}(\mathrm{CAT})_{10}$ & 5' -CATCATCATCATCATCATCATCATCATCAT-3' \\
\hline miR-155 & $5^{\prime}$-uuaaugcuaaucgugauagggg-3' \\
\hline
\end{tabular}

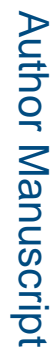

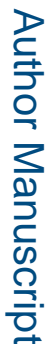

J Am Chem Soc. Author manuscript; available in PMC 2016 May 31. 


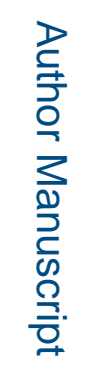

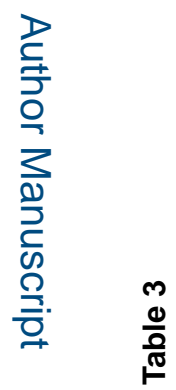

롤

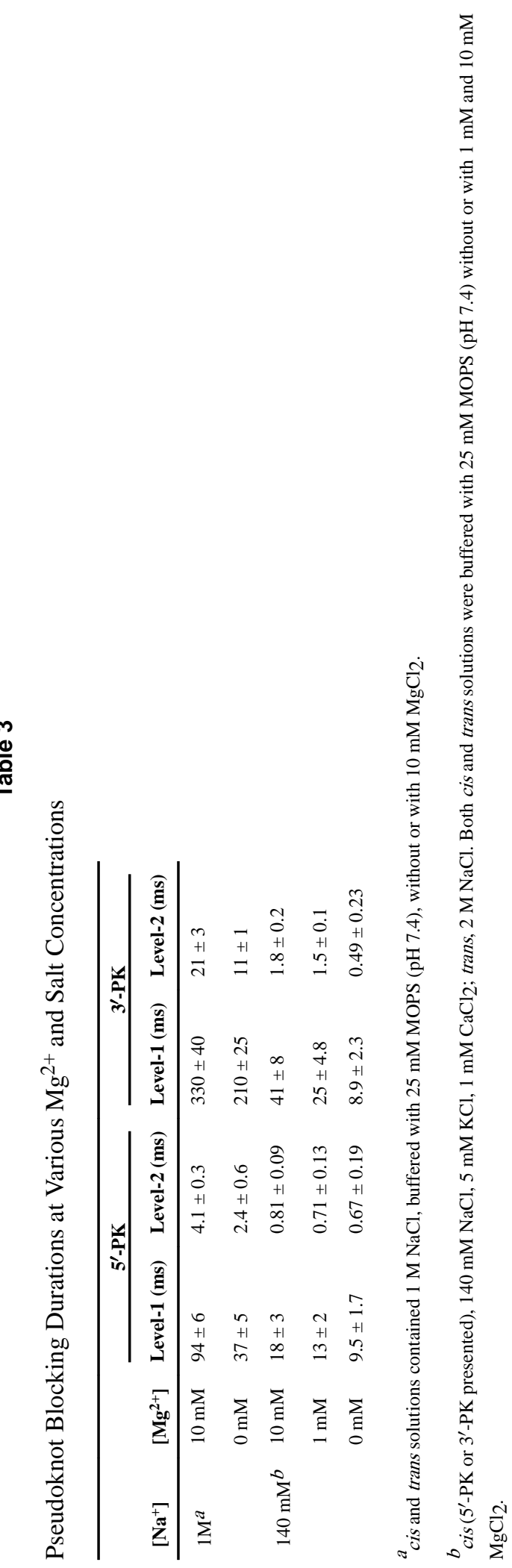

J Am Chem Soc. Author manuscript; available in PMC 2016 May 31. 